\title{
Mixed Stream Test Rig Winter FY-2011 Report
}

The INL is a

U.S. Department of Energy National Laboratory

operated by

Battelle Energy Alliance

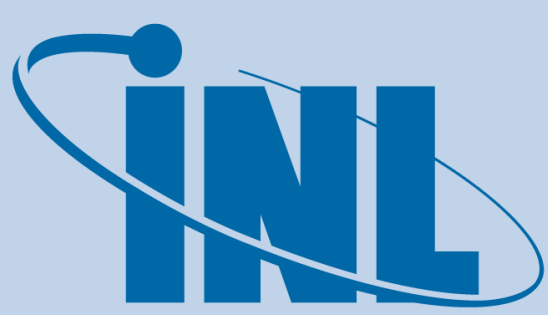

Idaho National Laboratory

April 2011

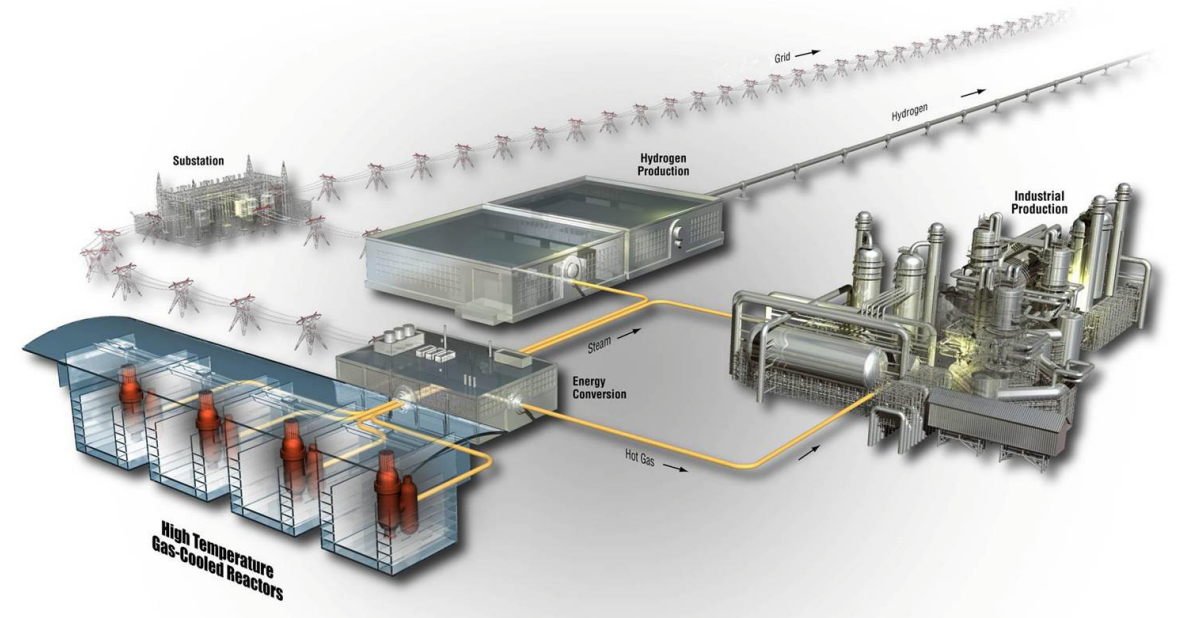




\section{DISCLAIMER}

This information was prepared as an account of work sponsored by an agency of the U.S. Government. Neither the U.S. Government nor any agency thereof, nor any of their employees, makes any warranty, expressed or implied, or assumes any legal liability or responsibility for the accuracy, completeness, or usefulness, of any information, apparatus, product, or process disclosed, or represents that its use would not infringe privately owned rights. References herein to any specific commercial product, process, or service by trade name, trade mark, manufacturer, or otherwise, does not necessarily constitute or imply its endorsement, recommendation, or favoring by the U.S. Government or any agency thereof. The views and opinions of authors expressed herein do not necessarily state or reflect those of the U.S. Government or any agency thereof. 
INL/EXT-11-21868

\section{Mixed Stream Test Rig Winter FY-2011 Report}

April 2011

Idaho National Laboratory

Next Generation Nuclear Plant Project

Idaho Falls, Idaho 83415

Prepared for the

U.S. Department of Energy

Office of Nuclear Energy

Under DOE Idaho Operations Office

Contract DE-AC07-05ID14517 



\section{Next Generation Nuclear Plant Project}

\section{Mixed Stream Test Rig Winter FY-2011 Report}

INL/EXT-11-21868

April 2011

Approved by:

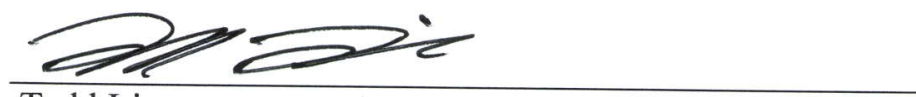

Tedd Lister

MISTER Materials Principal Investigator
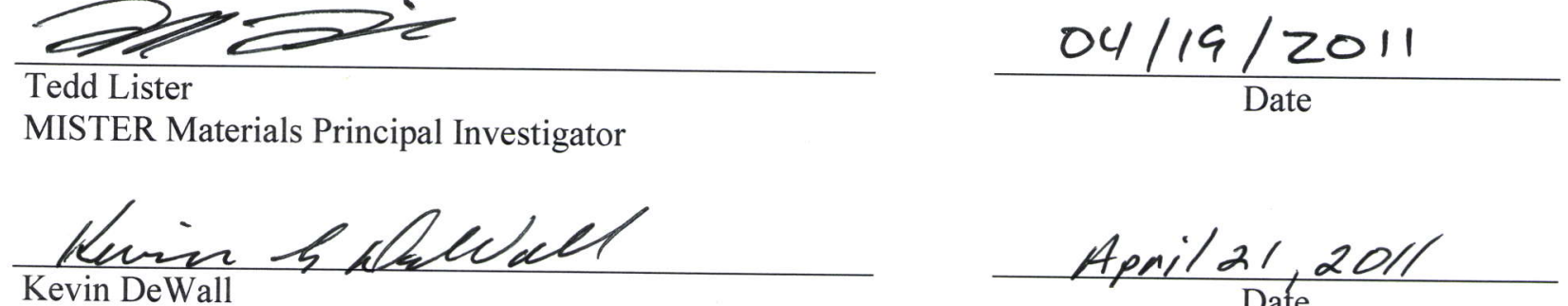

MISTER Experimental Principal Investigator
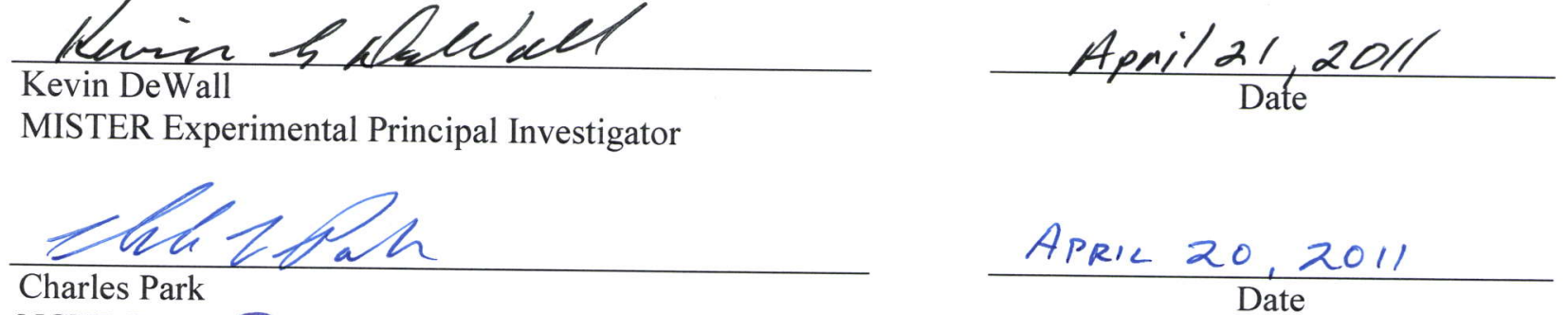

NGNP Process Heat Applications Systems Engineer
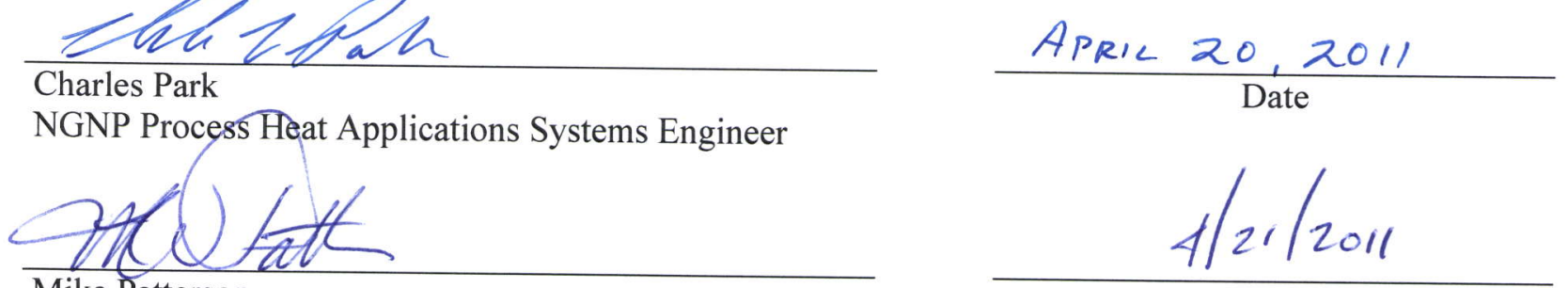

Mike Patterson

NGNP Process Heat Applications Manager

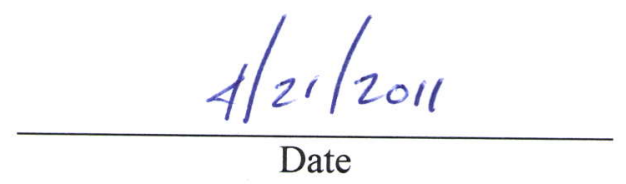





\section{SUMMARY}

This report describes the data and analysis of the initial testing campaign of the Mixed Stream Test Rig (MISTER) at Idaho National Laboratory (INL). It describes the test specimen selection, physical configuration of the test equipment, operations methodology, and data and analysis of specimens exposed in two environments designed to represent those expected for high temperature steam electrolysis (HTSE).

MISTER was assembled in FY 2010 to test high temperature materials within environments of gas compositions that are expected in the HTSE hydrogen production process. The test system is designed to provide realistic environments for studying the effects of high-temperature gas mixtures upon material samples. It does this with two separate gas streams of variable composition within a single furnace, exposing material samples to the gases at temperatures up to $1100^{\circ} \mathrm{C}$. Understanding the resulting material corrosion rates will help inform materials selection and qualification to ensure successful future performance. The initial test focuses on potential alloys for use in the oxygen and hydrogen streams from the HTSE process, although MISTER is also capable of controlling mixtures of $\mathrm{CO}, \mathrm{CO}_{2}, \mathrm{~N}_{2}$, and other gases.

Table S-1 provides a list of commercial alloys selected for the first MISTER test, which was initiated at $800^{\circ} \mathrm{C}$ to reflect gas temperatures at the HTSE anode and cathode. The cathode stream contained $70 \%$ hydrogen and $30 \%$ steam and the anode stream contained $50 \%$ oxygen and $50 \%$ nitrogen, which reflects expected HTSE gas conditions. The three Haynes alloys in Table S-1 were selected because of superior performance in previous INL HTSE testing. The final alloy was chosen because it has been selected for use in several NGNP heat transport system components. Alloy $800 \mathrm{H}$ is already listed in the ASME (American Society of Mechanical Engineers) nuclear section (ASME Code Section III Division 1), although the maximum use temperature and duration need to be increased to support use at the conditions expected for nuclear-integrated operations (including hydrogen production).

Table S-1. Alloys selected for MISTER testing.

\begin{tabular}{lll}
\hline Alloy & Oxide & Expected Performance \\
\hline Haynes 214 & alumina & excellent \\
Haynes 230 & chromia & excellent \\
Haynes HR-120 & chromia & excellent \\
Incoloy $800 \mathrm{H}$ & chromia & good* \\
\hline *ASME codified for nuclear applications at lower temperatures. & \\
\hline
\end{tabular}

Each material type was tested in both the cathode and anode streams and each had a sample removed after approximately 2 days, 1 week, 3 weeks, and 6 weeks, for a total of 32 specimens.

Over 900 hours of testing time were logged in the initial MISTER testing campaign. The specimens were exposed as outlined above to provide four different exposure times for each alloy. Following exposure the specimens were analyzed to determine weight gain, visual appearance, and chemical and microstructural features of the oxidized surfaces. FIB sectioning was performed to analyze the oxide-thickness and profile for the longest exposed specimens.

All specimens formed stable adherent oxide films. Alloy $800 \mathrm{H}$ showed the greatest oxidation in the simulated cathode stream mixture (steam + hydrogen gases) while showing very similar rates to the other chromia formers in the simulated anode stream mixture. Overall the oxidation rates were all below 5 $\mathrm{nm} / \mathrm{hr}$ for the longest tested specimen in both environments. Haynes 214, the sole alumina forming alloy, showed slightly lower oxidation rates overall. The two simulated gas mixtures showed similar oxidation 
rates under these conditions. Microscopic analysis determined that large chromia $\left(\mathrm{Cr}_{2} \mathrm{O}_{3}\right)$ crystallites over $5 \mu \mathrm{m}$ in diameter formed on the chromia forming alloys in the anode stream. Smaller crystallites were observed for the specimens exposed to the cathode stream. The results suggest that these materials were all suitable under the tested environment although additional testing is needed to evaluate the effect of high pressures, bounding gas mixtures and the potential for chromium evaporation and poisoning of the HTSE cells.

The current MISTER configuration represents an enhanced INL capability for testing materials in representative gas conditions, which is crucial for applied research with balance of plant systems in support of solid-oxide electrolysis cell development. Many process applications considered for the NGNP will require corrosion testing in high temperature gas mixtures, which MISTER is capable of supplying. In addition to the high temperatures, high pressures exist in many of these process applications. MISTER was thus designed and built so it could, with minor modifications, provide high pressure testing up to 1,000 psi. With further modification, it could test materials subjected to mechanical loading or pressure cycling at these high temperatures and pressures within a variety of gas compositions. Testing in these conditions will significantly advance the understanding of materials performance in representative environments for future heat exchangers, steam generators, circulators, seals, and instrument and control components. Other programs that could potentially benefit from testing in MISTER include life extension programs, hybrid energy systems and advanced reactor concepts. 


\section{CONTENTS}

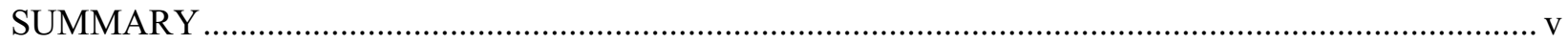

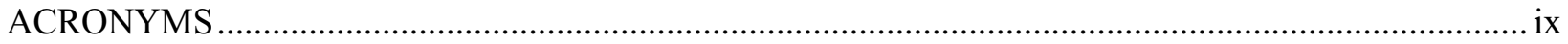

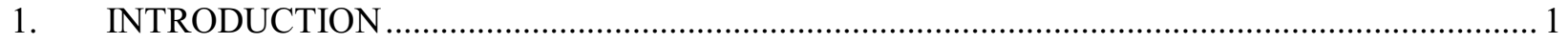

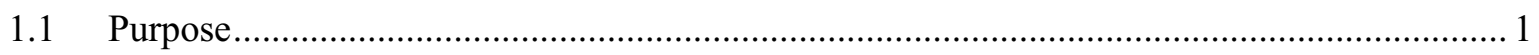

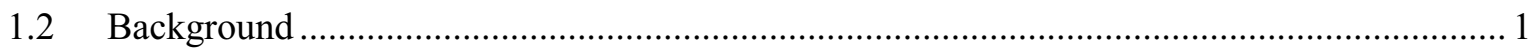

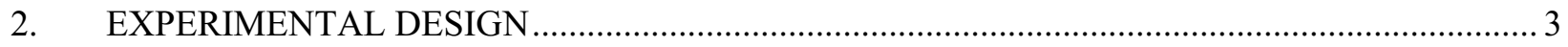

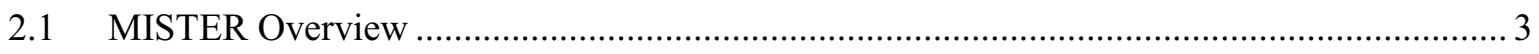

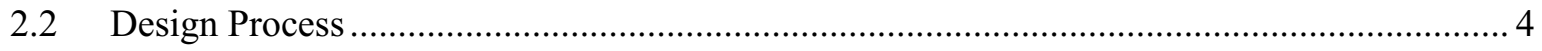

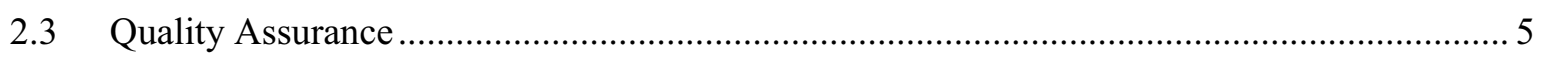

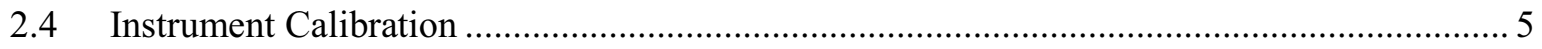

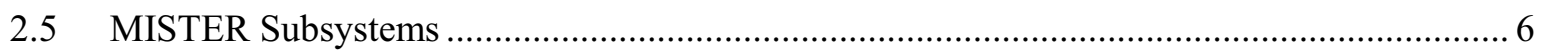

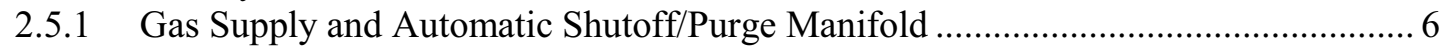

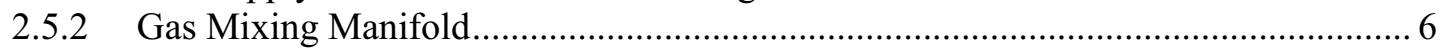

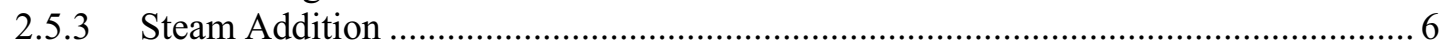

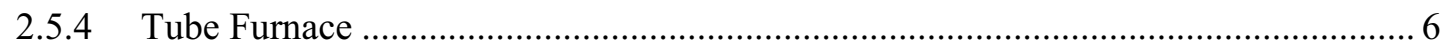

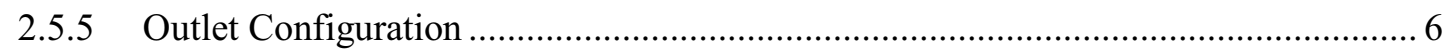

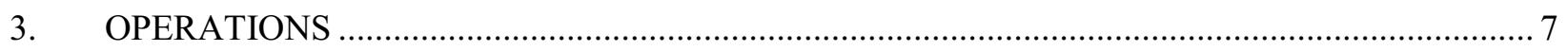

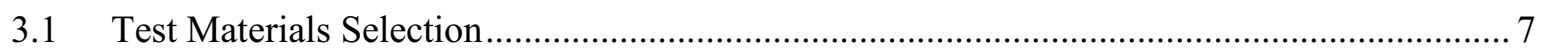

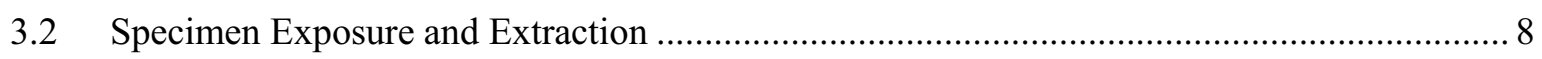

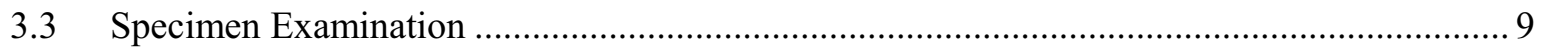

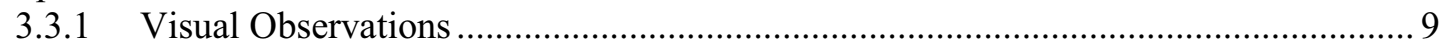

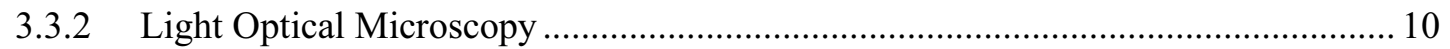

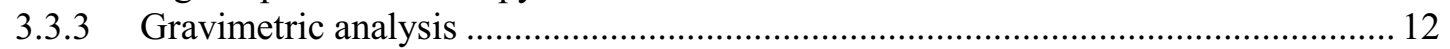

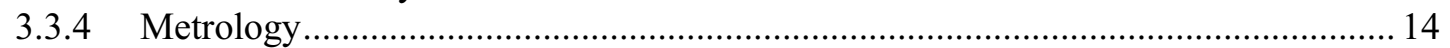

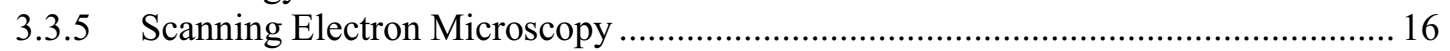

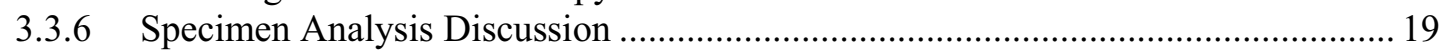

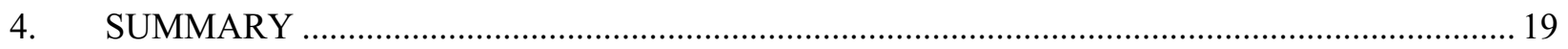

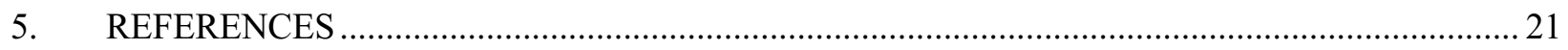

\section{FIGURES}

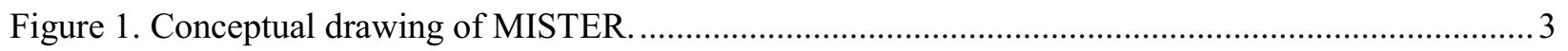

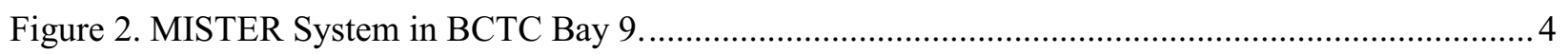

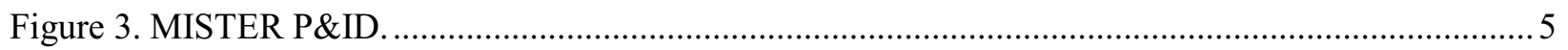

Figure 4. Color photograph of specimens exposed to the cathode stream. ............................................. 9

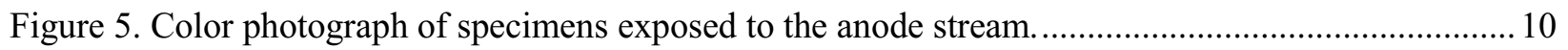

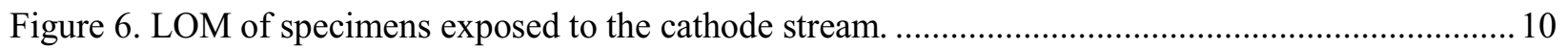


Figure 7. LOM of specimens exposed to the anode stream.

Figure 8. LOM micrographs of specimens exposed to the anode stream for 125 hours. Top micrograph is $\mathrm{H} 230$ at $500 \mathrm{X}$ and bottom is $800 \mathrm{H}$ at $1000 \mathrm{X}$.

Figure 9. Weight gain versus time for specimens exposed to the cathode stream.................................. 12

Figure 10. Weight gain versus time for specimens exposed to the anode stream.................................... 13

Figure 11. Oxidation rate measured for specimens exposed to the cathode stream................................. 13

Figure 12. Oxidation rate versus time for specimens exposed to the anode stream................................ 14

Figure 13. Surface roughness (Ra) measured for specimens exposed to the cathode stream. A value for the witness specimen is at $0 \mathrm{hrs}$

Figure 14. Surface roughness $\left(R_{a}\right)$ measured for specimens exposed to the anode stream. A value for the witness specimen is at $0 \mathrm{hrs}$.

Figure 15. OP micrograph for $800 \mathrm{H}-\mathrm{HY}-3$ exposed for $450 \mathrm{hrs}$ in the cathode stream. 16

Figure 16. SEM micrographs (3000X) for specimens exposed to the cathode stream. 17

Figure 17. SEM micrographs (3000X) for specimens exposed to the anode stream. .18

EDS spot analysis was performed during SEM analysis providing atomic\% values of elements in the oxide films. For brevity, an average value for the EDS spot analyses is provided in Table 4. The H214 shows a mix of alumina and chromia phases while the remaining specimens have chromium-manganese oxides, likely the spinel phase. An anomalous amount of Si was observed for specimens in the cathode stream. 18

Table 4: Atomic \% composition of elements from EDS spot analysis after 900 hours exposure. 19

\section{TABLES}

Table S-1. Alloys selected for MISTER testing. V

Table 2. Test matrix for testing HTSE cathode gas environment. ........................................................ 8

Table 3. Test matrix for testing HTSE anode gas environment. ............................................................... 8 


\section{ACRONYMS}

ASME American Society of Mechanical Engineers

$\mathrm{R}_{\mathrm{a}} \quad$ Average roughness

BCTC Bonneville County Technology Center

BOP Balance of Plant

EDS energy dispersive spectroscopy

DOE Department of Energy

HTSE high temperature steam electrolysis

INL Idaho National Laboratory

LFL lower flammability level

LI Laboratory Instruction

LOM light optical microscopy

MISTER Mixed Stream Test Rig

MSU Montana State University

NGNP Next Generation Nuclear Plant

OP optical profilometry

OSU Ohio State University

QLD Quality Level Determination

$\mathrm{R} \& \mathrm{D} \quad$ research and development

SEM scanning electron microscopy

SOEC solid-oxide electrolysis cell

SOFC solid-oxide fuel cell

SPECTR Small Pressure Cycling Test Rig

TLV Threshold Limit Value

UPS Uninterruptable Power Supply 


\section{Mixed Stream Test Rig Winter FY-2011 Report}

\section{INTRODUCTION}

\subsection{Purpose}

This report describes the work accomplished to assemble, start-up, and initiate testing in the Mixed Stream Test Rig (MISTER) at Idaho National Laboratory (INL). It describes the reasons for establishing this capability, physical configuration of the test equipment, operations methodology, initial operations, and test results. Setup and startup of the MISTER test rig is documented in the "MISTER Startup Report" (INL/EXT-11-20961), dated February 2011.

MISTER was assembled in FY 2010 to test high temperature materials within environments of gas compositions that are expected in the high temperature steam electrolysis (HTSE) hydrogen production process. The test system is designed to provide realistic environments for studying the effects of high-temperature gas mixtures upon material samples. It does this with two separate streams within a single furnace of hydrogen and oxygen mixtures that can be exposed to temperatures up to $1100^{\circ} \mathrm{C}$. Understanding the resulting material corrosion rates will help inform materials selection and qualification to ensure successful future performance.

The current MISTER configuration represents an enhanced capability for INL. MISTER was also designed and built so that, with minor modifications, it can provide high pressure testing at up to $7 \mathrm{MPa}$ $(1,000 \mathrm{psi})$. With further modification, it could test materials subjected to load or cycling at these high temperatures and pressures within a variety of gas compositions. This testing will significantly advance the understanding of materials performance in the HTSE process and provide the capability for testing materials in other high temperature hybrid energy systems. Because of the ability to greatly vary gas compositions (both type and quantity), it can be used to test materials for future heat exchangers, steam generators, circulators, seals, and instrument and control components.

\subsection{Background}

In response to a national strategic need identified in the Energy Policy Act of 2005 to promote reliance on safe, clean, economic nuclear energy and to establish a greenhouse-gas-free technology for the production of hydrogen, the Department of Energy (DOE) defined a mission need to develop new, advanced nuclear reactor and hydrogen production technologies. The Next Generation Nuclear Plant (NGNP) represents an integration of high-temperature reactor technology with advanced capabilities for producing hydrogen, electricity, and/or process heat. Battelle Energy Alliance, LLC is advancing this technology at INL in conjunction with partners from other national laboratories, industry and academia.

Multiple INL organizations collaborated to establish the MISTER capability at INL, and the first test planned and currently underway supports the selection of HTSE materials. To this end, NGNP Process Heat Applications and HTSE research and development (R\&D) organizations were fully integrated during development. MISTER and HTSE test equipment are consequently co-located in the Bonneville County Technology Center (BCTC).

Significant work was accomplished in FY 2010 and continues in FY 2011 in selecting, defining, and evaluating potential industrial applications that benefit from NGNP integrated hydrogen production. That work indicates there is a need to demonstrate material performance, such as corrosion, in gaseous heat transfer system piping and components that connect the industrial applications. MISTER is a capability that can test corrosion of potential materials in a variety of gas environments. 
MISTER complements other test capability currently being fabricated or planned to support development of technologies needed for NGNP deployment. Although each of these capabilities can provide important, unique data for high temperature and pressure components, MISTER is designed to replicate the aggressive mixed gas environments expected for process heat applications components on multiple small specimens to measure corrosion in specific conditions. The high temperature oxygen- and hydrogen-based gas streams at the anode and cathode of the HTSE solid-oxide electrolysis cells (SOECs) are two of these environments. Hence, scoping tests of potential materials for use in these HTSE gas streams were selected to define operating conditions for the first MISTER tests. 


\section{EXPERIMENTAL DESIGN}

\subsection{MISTER Overview}

MISTER will provide the desired environments for material testing through two independent piping systems, one for flammable mixtures (hydrogen, $\mathrm{CO}_{2}$, etc.) and another for oxidizing mixtures (oxygen, air, etc.). The flow path for each is a once-through design where the gases are mixed, heated, passed over the samples, and then exhausted by venting through the roof of the laboratory. The gas streams are piped in a configuration that enables gas exposure of different components, specimen configurations or bipolar corrosion measurements during the same experimental run. Bipolar testing refers to the ability to flow different gas compositions on opposing sides of the same sample. The two parallel streams share a co-located gas supply system, and all tube fittings are positioned outside the furnace. The piping system is assembled with standard Swagelok-type fittings and tubing with a maximum allowable working pressure of $7 \mathrm{MPa}(1,000 \mathrm{psi})$. The flammable mixtures piping system is electrically grounded and bonded. A conceptual diagram of the MISTER system is shown in Figure 1. No isolation valves are present in the piping from the furnace to the vent so over-pressurization from heating is not possible.

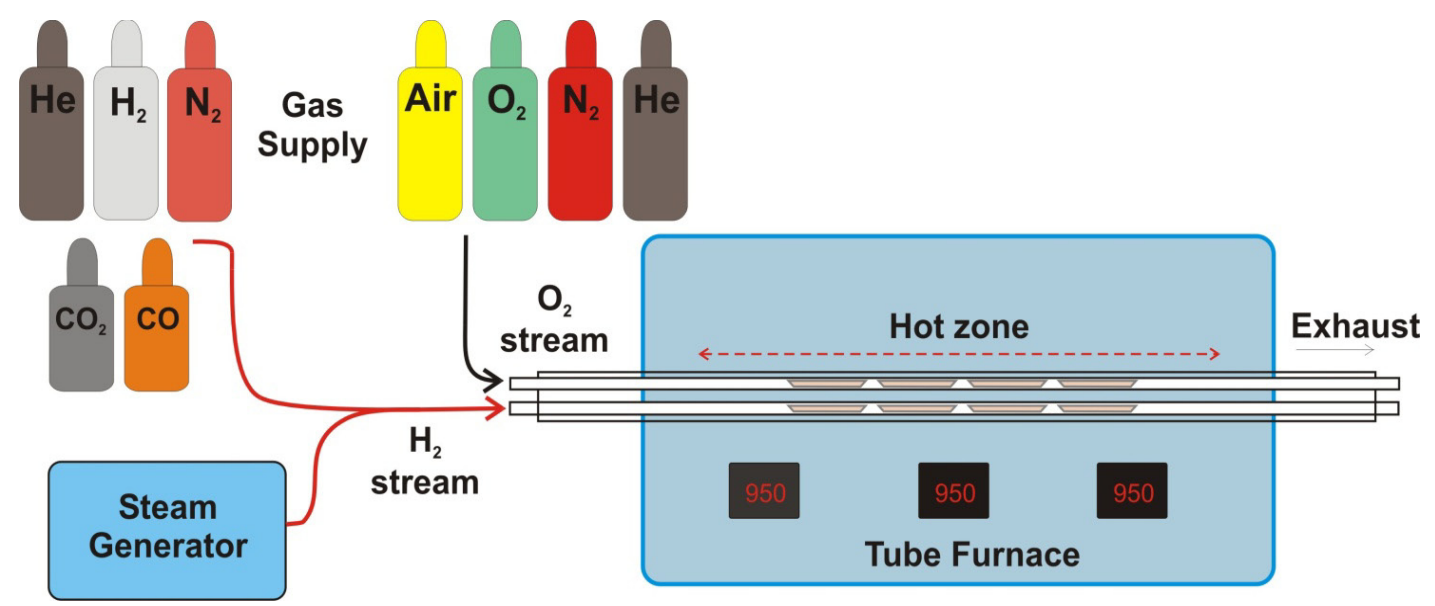

Figure 1. Conceptual drawing of MISTER.

The configuration allows seven gases to be connected to the gas supply: hydrogen, nitrogen, carbon monoxide, carbon dioxide, compressed air, oxygen, and helium. These gases are supplied from compressed gas cylinders. Compressed air can be supplied from building utilities for low-pressure testing. To accommodate long experiments, gas cylinders are connected to a changeover regulator assembly that allows bottle change-out without loss of gas flow. Pressure relief valves are installed in each supply line and set to $7 \mathrm{MPa}(1,000 \mathrm{psi})$. Other gases can also be used if they are compatible with gas chemistry and tubing materials.

Figure 2 shows a photo of the MISTER system in the BCTC with the experimental control monitors in front of the tube furnace. At the inlet to the furnace (between the furnace and the wall) is the rack that holds the mass flow controllers, steam generator, metering pump, and other gas conditioning components. To the right of the photo (not shown) are the compressed cylinders for gas supply. 


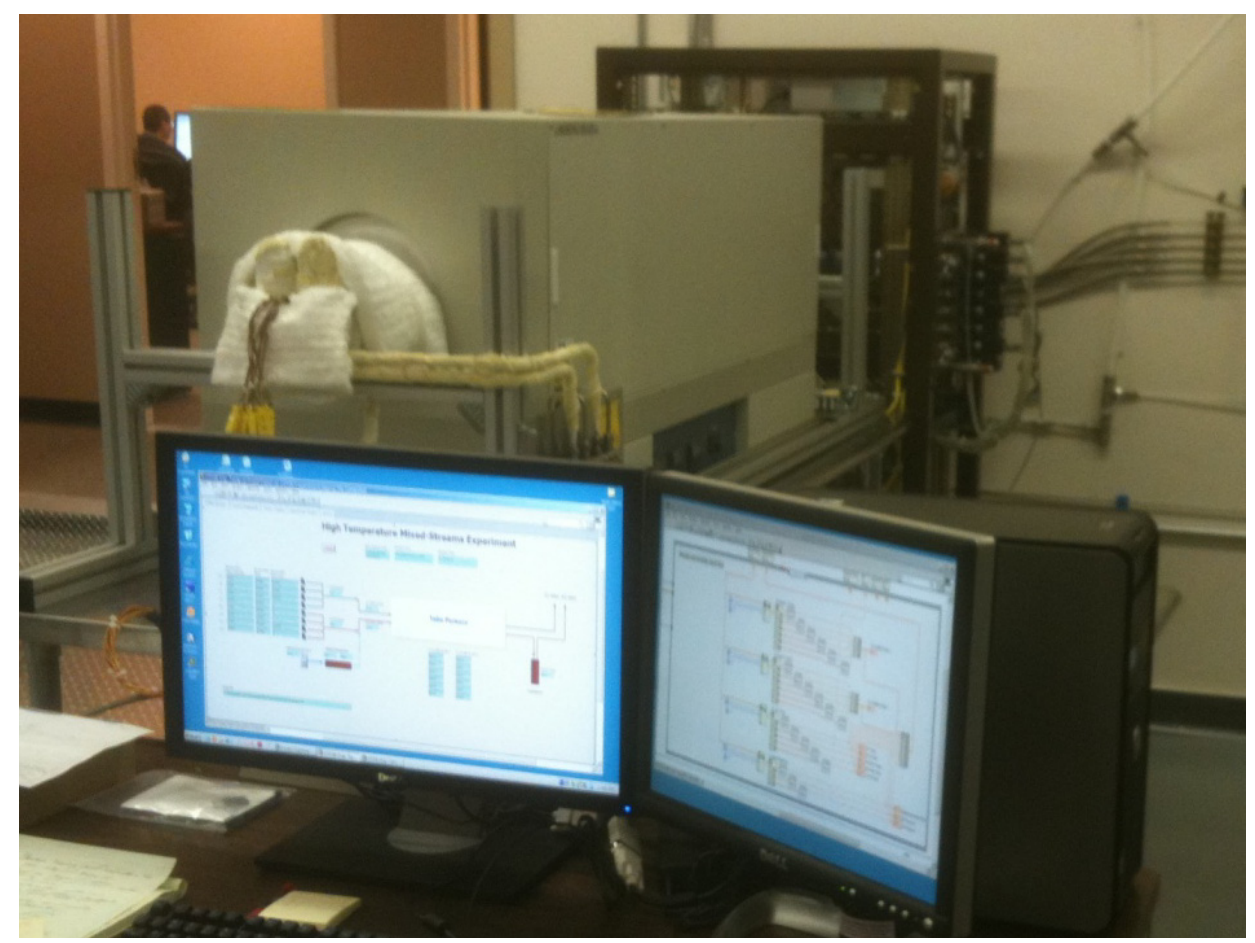

Figure 2. MISTER System in BCTC Bay 9.

\subsection{Design Process}

Early design and scoping efforts identified an opportunity to build upon INL experience with earlier high temperature materials testing with similar gases. A complete process model of MISTER was developed using HYSYS process modeling software to evaluate gas mixtures, flows, pressures, and temperatures to predict system performance and identify areas of concern. It also allowed a degree of fine-tuning to ensure that the testing environments replicate expected future material demands. The piping and instrumentation diagram (P\&ID) is shown in Figure 3. A hazardous gas shutdown and purge system was designed to automatically place the experiment in a safe state in response to the BCTC Bay 9 Hazardous Gas Alarm System, while preventing damage to experiment material samples. The result was that the MISTER design expanded test capabilities to include higher temperature, pressurized gas streams, and additional gas mixing capabilities.

Automation including an uninterruptible power supply (UPS) system for the data acquisition/system controller computer system is incorporated, making the system reliable for unattended operation. In the event a long power failure exceeds the capacity of the UPS, resulting in deactivation of the systemcontroller computer, the furnace simply cools down and the gas flows switch to an inert gas purge. No hazard exists from loss of power, even if the power subsequently comes back on, because of the automatic gas shutoff positions. The hazardous gas supply valves will fail shut on a loss of power and the helium gas supply valve will fail open to perform a purge of the system. 


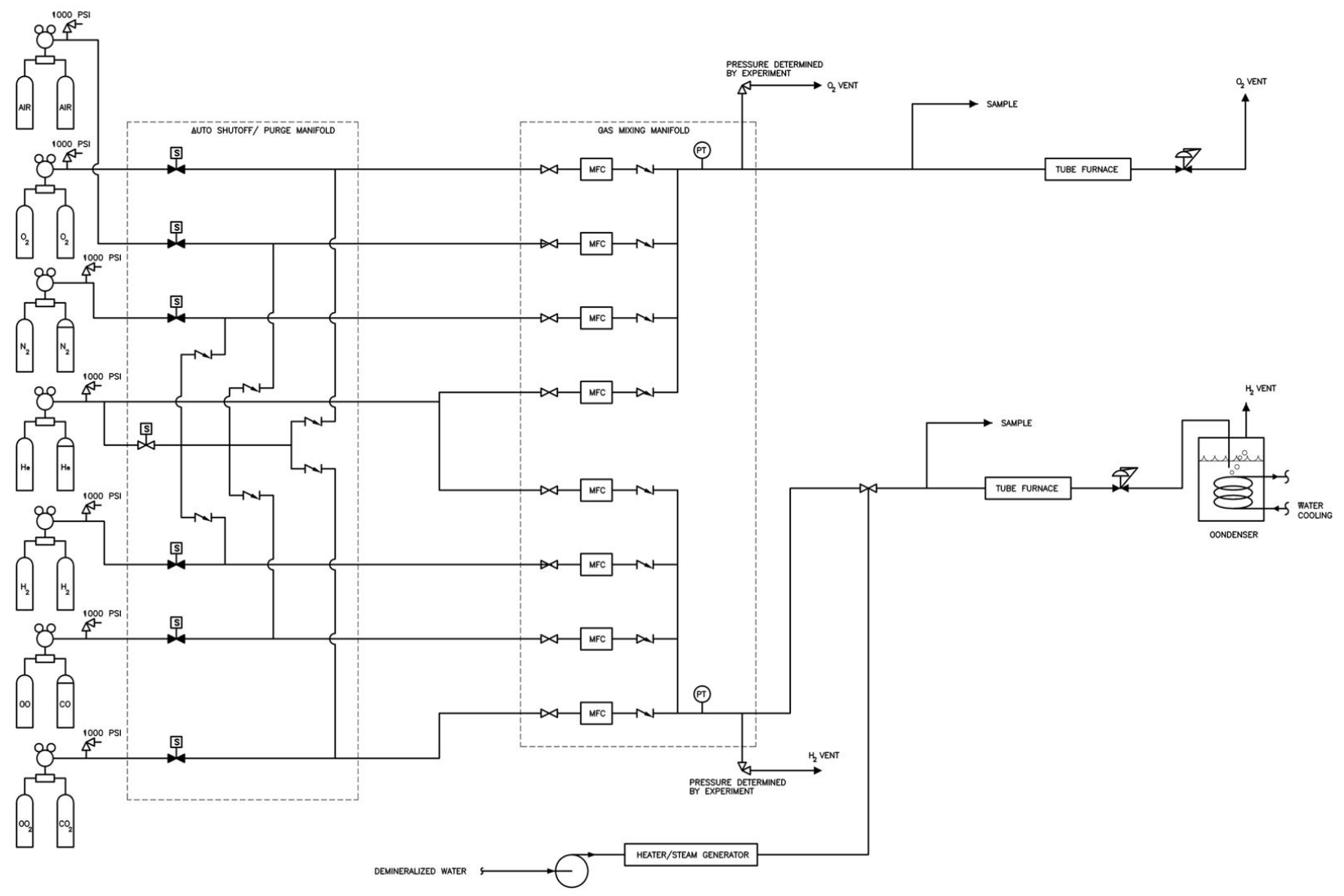

Figure 3. MISTER P\&ID.

\subsection{Quality Assurance}

A Quality Level Determination (QLD) performed on the MISTER experiment design and assembly determined it to be Quality Level (QL) 3. Because the first experiment is a scoping test, the data use was also judged to be QL-3. Separate QLDs for each test matrix will be performed for future experiments and the quality level for each will be determined based on intended data use. It is anticipated that if the data's use is for ASME (American Society of Mechanical Engineers) code development, design of critical systems, or supporting high impact programmatic decisions, additional rigor will be required, resulting in a QL-2 determination for those future experiments. Examples of the impact of a QL-2 determination might be expanded instrumentation calibrations, tighter controls of gas impurities, or stricter chain of custody requirements for the specimens. Nothing in the design and fabrication of MISTER would prevent application of such rigorous controls if the data use requires it.

\subsection{Instrument Calibration}

The instruments maintained and calibrated by INL Calibration Services are mass flow controllers, a metering pump, and pressure transducers. Factory calibration of the new devices provided sufficient calibration rigor during the first calibration interval. Other instruments, such as thermocouples, pressure regulators, and back pressure control valves that were used to control the test system for these initial scoping tests did not require calibration because the corrosion data is for scoping purposes. Response to control systems was checked during shakedown testing. Future testing for uses such as ASME Code qualification and generation of design data will be performed under appropriate test procedures that specify the needed calibrations. 


\subsection{MISTER Subsystems}

\subsubsection{Gas Supply and Automatic Shutoff/Purge Manifold}

A hazardous gas monitoring system, employed in the laboratory for safety, monitors four gases (CO, $\mathrm{CO}_{2}$, hydrogen, and oxygen) in two locations. The system has relay outputs, display readout, visual and audible alarms, and an auto phone dialer. The relay outputs are used to automatically shut down the experimental gas flow if any gas alarm is activated. Upon receipt of a shutdown signal, six normally closed (fail-closed) solenoid valves isolate the hazardous gas supplies and a normally open (fail-open) solenoid valve initiates inert purge gas (helium) through all lines. Check valves prevent gas mixing in the automatic shutoff/purge system.

The outlet of the automatic shutoff/purge system provides feed to the gas mixing manifold through patch lines allowing reconfiguration of the specific gases supplied to each port. For example, compatible gases such as helium and nitrogen can be supplied to one or both of the flammable and oxidizer mixture streams.

\subsubsection{Gas Mixing Manifold}

The discharge from the gas supply system feeds the gas mixing manifold, including the individual mass flow controllers for each gas to produce the desired gas mixtures for the experimental campaign. Up to four individual gases can be mixed to produce each of the two separate outlet streams. Pressure relief valves on the outlet streams are set below the maximum pressure of the specific experiment components running through the remainder of the flow system. The maximum allowable working pressure of the gas mixing manifold is also set at $7 \mathrm{MPa}(1,000 \mathrm{psi})$.

\subsubsection{Steam Addition}

A metering pump and electric powered steam generator are used to add steam to the flammable mixtures gas stream. The associated lines are heat-traced to prevent steam condensation. The metering pump controls the steam addition and hence, the steam-to-gas ratio in the affected outlet stream.

\subsubsection{Tube Furnace}

The two gas streams flow through the furnace into $3 / 4$ inch schedule 40 Haynes 214 pipes that are large enough to place small sample coupons inside. The tube furnace is a Lindberg Model 55666 B COM with a maximum operating temperature of $1100^{\circ} \mathrm{C}$. It has a $90 \mathrm{~cm}(36 \mathrm{inch})$ heated chamber with three zones of control (first zone is 9 inches, middle zone 18 inches, last zone 9 inches) in a double-shell construction. The furnace is rated for $11 \mathrm{~kW}$ at $240 \mathrm{VAC}$. Since the laboratory supplies only $208 \mathrm{VAC}$, the furnace can produce $8.3 \mathrm{~kW}$. The tube furnace is controlled with three separate programmable controllers with dual light-emitting diode displays of the set point and actual temperature. The tube furnace also has separate over-temperature protection. This consists of a digital high-limit controller with separate thermocouple and magnetic contactor disconnect on the heating elements.

\subsubsection{Outlet Configuration}

Atmospheric pressure experiments do not have valves between the furnace and the vents. Future pressurized testing will require that a backpressure regulator valve be installed downstream of the furnace to provide pressure control in the system. The oxidizer stream will discharge directly to the building oxygen vent. The flammable stream will be directed to a steam condenser to both cool and remove water from the stream. The outlet of the steam condenser will proceed directly to a building hydrogen vent. 


\section{OPERATIONS}

Alloy specimens were placed on ceramic "boats" on January 11, 2011, and inserted into the MISTER Haynes 214 tubes. Specimens of four alloys were exposed to environments simulating the cathode (hydrogen stream) and anode (oxygen stream) gases. This test used gas composition of $70 \%$ hydrogen and $30 \%$ water for hydrogen stream and $50 \%$ nitrogen gas and $50 \%$ oxygen for the oxygen stream at $800^{\circ} \mathrm{C}$. These conditions were identified during modeling of the HTSE system (but at ambient conditions). A commercial HTSE plant is expected to operate at a pressure of $5 \mathrm{MPa}$ (725 psi) and high pressure testing will eventually be needed to demonstrate viability of the technology at larger scales. Actual specimen exposure was included in the start-up testing of MISTER because it allows identification of specimen management issues during a scoping test when the consequences of lost data are low.

\subsection{Test Materials Selection}

Initial testing in MISTER supports HTSE technology development. Exterior to the actual SOECs, HTSE system components such as gas manifolds are exposed to super-heated $\left(800-950^{\circ} \mathrm{C}\right)$ hydrogen/steam and oxygen/nitrogen gas mixtures. Corrosion products from potential balance-of-plant (BOP) materials may contaminate SOECs and cause reduced performance. It is therefore essential to select and qualify materials with excellent corrosion performance under reducing and/or oxidizing environments at temperatures up to $950^{\circ} \mathrm{C}$ for lifetimes up to 40,000 hours.

Previous INL test results showed that about half of the alloys tested appeared quite stable to oxidation and spalling after 1,000 hours. In particular, alumina $\left(\mathrm{Al}_{2} \mathrm{O}_{3}\right)$ forming alloys showed very thin oxide films and minimal weight gain. Manganese-chromium spinel $\left(\mathrm{MnCr}_{2} \mathrm{O}_{4}\right)$ forming alloys such as Haynes 230 and HR-120 were also promising. These alloys form a mixture of spinel and chromia $\left(\mathrm{Cr}_{2} \mathrm{O}_{3}\right)$ phases. Incoloy $800 \mathrm{H}$ and other chromia-forming alloys showed mixed results, where significant spalling was observed in the oxygen/nitrogen simulated stream. Initial MISTER testing will validate operation of the test apparatus and develop some preliminary scoping data for candidate material selection. Recent modeling work within the HTSE group targets an operating temperature of $800^{\circ} \mathrm{C}$ at $5 \mathrm{MPa}$. A variety of gas mixtures are present within the HTSE system, but the first test will use a median value of $70 \%$ hydrogen $/ 30 \%$ steam for the cathode stream and $50 \%$ oxygen $/ 50 \%$ nitrogen for the anode stream.

Table 1 provides a list of commercial alloys and compositions for this testing. The first three alloys were selected because of superior performance in previous INL BOP testing. The $800 \mathrm{H}$ alloy was selected for fabrication of other NGNP heat transport system components. Alloy $800 \mathrm{H}$ is already listed in the ASME nuclear section (ASME Code Section III Division 1), although the maximum use temperature and duration need to be increased if it is to be used as a pressure boundary material in HTSE gas streams at $800^{\circ} \mathrm{C}$.

Table 3-1 Alloy Composition (\%)

\begin{tabular}{|c|c|c|c|c|}
\hline & $\begin{array}{c}\text { Haynes } \\
\mathbf{2 1 4}\end{array}$ & $\begin{array}{c}\text { Haynes } \\
\mathbf{2 3 0}\end{array}$ & $\begin{array}{c}\text { Haynes HR- } \\
\mathbf{1 2 0}\end{array}$ & $\begin{array}{c}\text { Alloy } \\
\mathbf{8 0 0 H}\end{array}$ \\
\hline $\mathbf{C r}$ & 16.2 & 22.12 & 25.02 & 20.63 \\
\hline $\mathbf{F e}$ & 3.55 & 0.85 & Bal & 46.6 \\
\hline $\mathbf{M n}$ & 0.16 & 0.44 & 0.68 & 0.64 \\
\hline $\mathbf{A l}$ & 4.19 & 0.36 & 0.1 & 0.54 \\
\hline $\mathbf{N i}$ & $\mathrm{Bal}$ & $\mathrm{Bal}$ & 37.2 & 30.33 \\
\hline $\mathbf{W}$ & $<0.001$ & 14.02 & $<0.1$ & - \\
\hline $\mathbf{M o}$ & $<0.1$ & 1.23 & 0.19 & - \\
\hline $\mathbf{T i}$ & $<0.001$ & $<0.01$ & $<0.01$ & 0.54 \\
\hline $\mathbf{C o}$ & $<0.01$ & 0.08 & 0.12 & 0.04 \\
\hline $\mathbf{C u}$ & - & 0.05 & 0.09 & 0.04 \\
\hline $\mathbf{S i}$ & 0.03 & 0.39 & 0.52 & 0.32 \\
\hline $\mathbf{C}$ & 0.04 & 0.1 & 0.051 & 0.07 \\
\hline $\mathbf{B}$ & 0.002 & 0.002 & 0.002 & - \\
\hline $\mathbf{S}$ & $<0.002$ & $<0.002$ & $<0.002$ & 0.0002 \\
\hline
\end{tabular}


The test matrix specified that each material type be tested in both the hydrogen and oxygen streams and that a specimen of each material be removed after approximately 2 days, 1 week, 3 weeks, and 6 weeks, making a total of 32 samples. This provides a distribution of exposure values to trend the weight gain and determine any changes in oxidation behavior during the exposure. The exposure was performed at $800^{\circ} \mathrm{C}$ for the entirety of the test. The test matrix for the cathode gas environment (hydrogen) is shown in Table 2 with a hydrogen feed rate of $0.5 \mathrm{~L}$ per minute and water feed rate of $0.161 \mathrm{~mL}$ per minute. The test matrix for the anode gas environment (oxygen) is shown in Table 3, with both oxygen and nitrogen feed rates of $0.292 \mathrm{~L}$ per minute.

Table 3-2 Test matrix for testing HTSE cathode gas environment.

\begin{tabular}{cccc}
\hline No. & Alloy & Type & $\begin{array}{c}\text { Approx } \\
\text { Exposure } \\
\text { (hrs) }\end{array}$ \\
\hline 1 & HR-120 & chromia & 48 \\
2 & HR-120 & chromia & 168 \\
3 & HR-120 & chromia & 504 \\
4 & HR-120 & chromia & 1,000 \\
5 & H214 & alumina & 48 \\
6 & H214 & alumina & 168 \\
7 & H214 & alumina & 504 \\
8 & H214 & alumina & 1,000 \\
9 & H230 & chromia & 48 \\
10 & H230 & chromia & 168 \\
11 & H230 & chromia & 504 \\
12 & H230 & chromia & 1,000 \\
13 & $800 \mathrm{H}$ & chromia & 48 \\
14 & $800 \mathrm{H}$ & chromia & 168 \\
15 & $800 \mathrm{H}$ & chromia & 504 \\
16 & $800 \mathrm{H}$ & chromia & 1,000 \\
\hline
\end{tabular}

Table 3-3 Test matrix for testing HTSE anode gas environment.

\begin{tabular}{|c|c|c|c|}
\hline No. & Alloy & Type & $\begin{array}{c}\text { Approx } \\
\text { Exposure } \\
(\mathrm{hrs})\end{array}$ \\
\hline 1 & HR-120 & chromia & 48 \\
\hline 2 & HR-120 & chromia & 168 \\
\hline 3 & HR-120 & chromia & 504 \\
\hline 4 & HR-120 & chromia & 1,000 \\
\hline 5 & $\mathrm{H} 214$ & alumina & 48 \\
\hline 6 & $\mathrm{H} 214$ & alumina & 168 \\
\hline 7 & H214 & alumina & 504 \\
\hline 8 & $\mathrm{H} 214$ & alumina & 1,000 \\
\hline 9 & $\mathrm{H} 230$ & chromia & 48 \\
\hline 10 & $\mathrm{H} 230$ & chromia & 168 \\
\hline 11 & $\mathrm{H} 230$ & chromia & 504 \\
\hline 12 & $\mathrm{H} 230$ & chromia & 1,000 \\
\hline 13 & $800 \mathrm{H}$ & chromia & 48 \\
\hline 14 & $800 \mathrm{H}$ & chromia & 168 \\
\hline 15 & $800 \mathrm{H}$ & chromia & 504 \\
\hline 16 & $800 \mathrm{H}$ & chromia & 1,000 \\
\hline
\end{tabular}

Thin plate specimens from 1/8-1/16-in.-thick plate were cut to $1 \times 1$-cm squares and a 600 -grit finish was applied prior to testing. Witness specimens were characterized in as-received or as-prepared condition and gravimetric analysis was used to measure weight change during the experiment.

\subsection{Specimen Exposure and Extraction}

Specimens were inserted into the MISTER furnace in ziconia boats secured together using both inconel wire and a ceramic rod bonded along the entire length using alumina paste. An inconel wire was attached to the last boat for retrieval. After system closure, inert nitrogen gas was initiated and heating of tube furnace started. Heating required approximately 4 hours. When the furnace reached operating temperature the specified gas streams were introduced. For each specimen removal, the gas streams were first switched to nitrogen gas then the furnace heating turned off. The furnace was turned off so it could cool sufficiently to allow the specimens to be safely removed (generally overnight). Specimens were removed the following morning and then the heating sequence described above repeated. 
Upon removal of the alumina boat for the first pull it was observed that one of the boats in the cathode stream had cracked. This boat was glued and both sets of boats reinserted with their samples. When the specimen and boats were removed for the second pull the repaired alumina boat was replaced by a quartz boat. This new boat design employed a quartz rod to insert and remove specimens. This new boat was considered a significant improvement over the ceramic boats and will be employed for future testing. After the third pull a small repair was performed on the remaining specimen boats for the anode stream. This might have led to some unintended contamination of one of the specimens.

There were a couple interruptions in the exposure due to a trigger of the automatic shutdown system. The cause of these shutdowns has been traced to the switch over characteristics of the UPS allowing the shutdown system relay to trip. The UPS has subsequently been replaced with an on-line UPS. The shutdown system switches flow from reactive gases to the He safe gas to stop oxidation processes. The exposure time was estimated because the trigger for these events was not captured in the software. As it was not essential to expose for precise time periods, this was not deemed an issue and thus exposures differ from those labeled in Tables 2 and 3.

\subsection{Specimen Examination}

Examination of specimens following exposure was performed using visual examination, gravimetric analysis, light optical microscopy (LOM), optical profilometry (OP) and surface and cross-sectional scanning electron microscopy (SEM). For SEM analysis only the longest exposed specimen was analyzed. At the time of this report, cross-sectioning analysis of the oxide film was delayed due to an instrument failure. This data will be added during a later revision.

\subsubsection{Visual Observations}

Specimen were photographed and characterized by visual appearance. Figure 4 shows specimens after exposure to the cathode stream. The H214 specimens, being an alumina former, have a different appearance due to the transparency of alumina film. An iridescent character was observed at the two lowest exposure times. This is due to interference effects for variations in oxide film thickness. The H230 and HR-120 specimens have a similar gray green appearance while the $800 \mathrm{H}$ is a lighter grey with dark areas increasing in area with time.

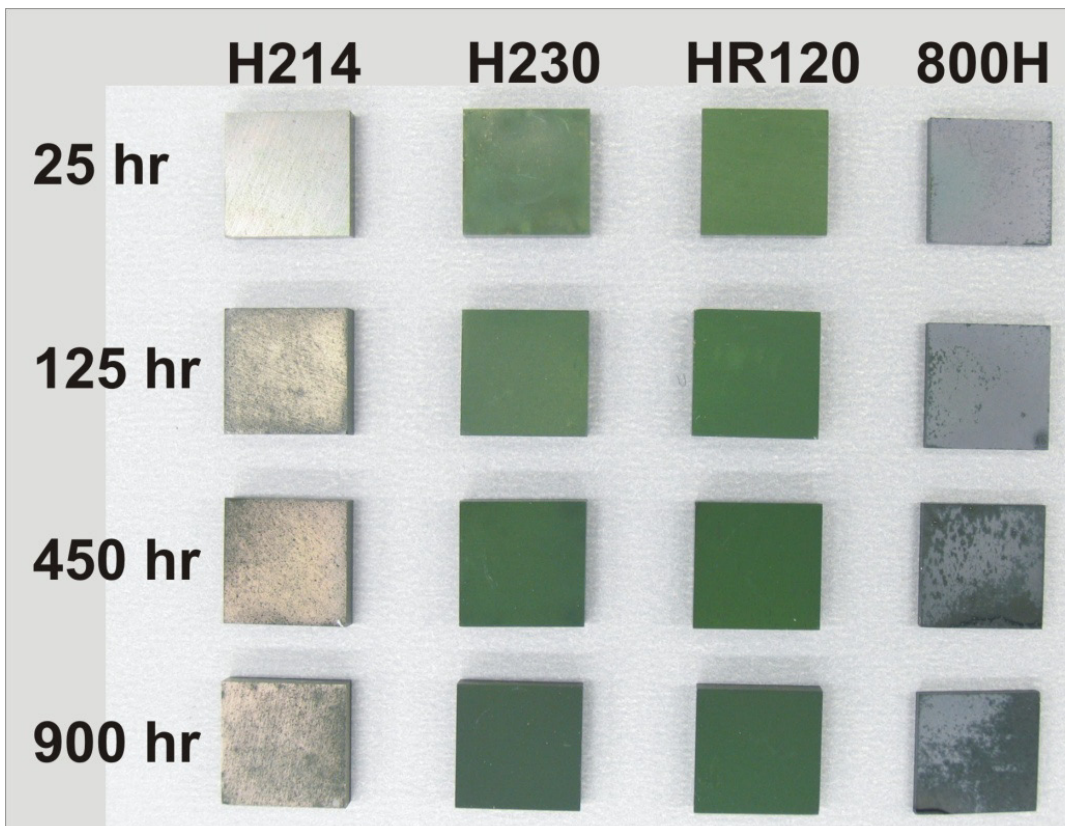

Figure 4. Color photograph of specimens exposed to the cathode stream. 
Figure 5 shows specimens exposed to the anode stream. The H214 specimens again show a more transparency but with more iridescent character than those exposed to the cathode stream. H230 and HR-120 specimens exposed to the anode stream are less green in color but have a similar dull texture to cathode stream exposed specimens. However, the $800 \mathrm{H}$ specimens are a darker grey than observed for the specimens exposed to the cathode stream. For the H230 specimen exposed for 900 hours there appears to be a precipitate that could be from the adhesive used to hold the specimen boats together. No evidence of spalling was observed.

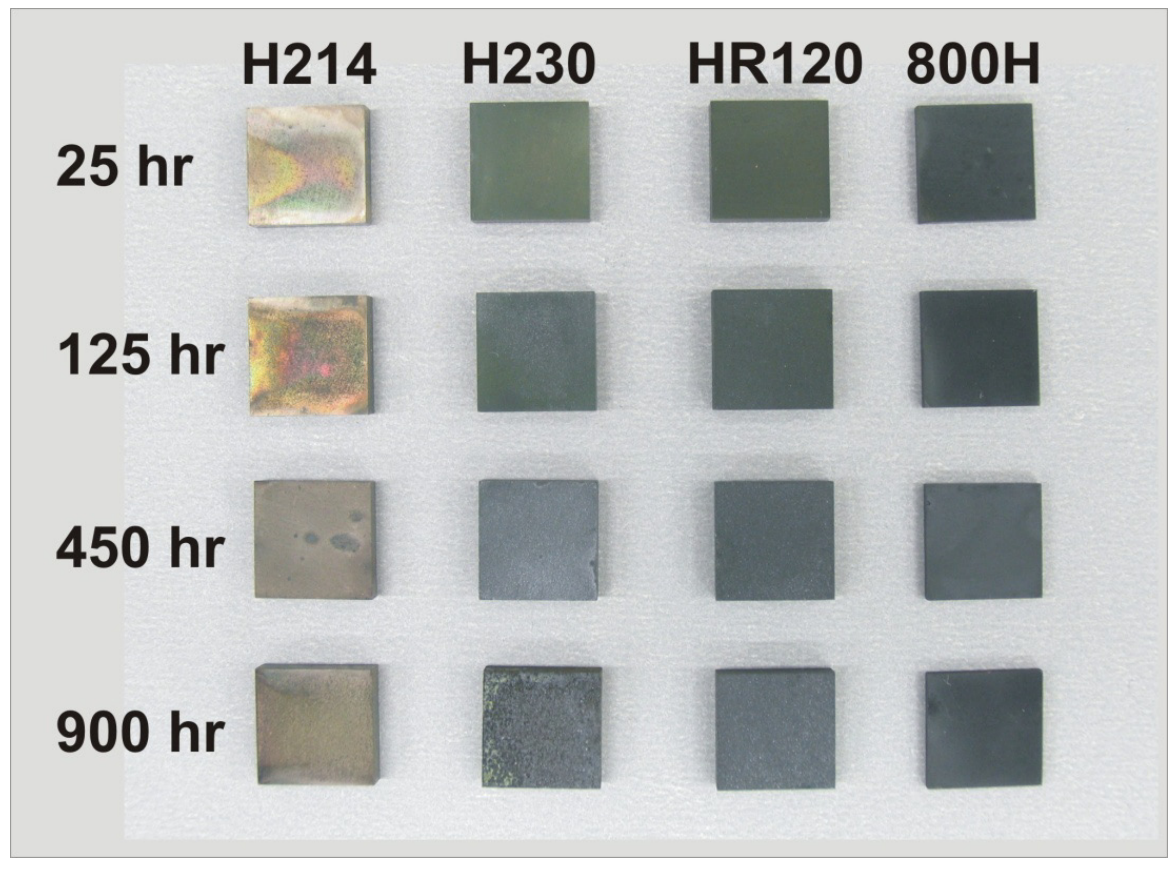

Figure 5. Color photograph of specimens exposed to the anode stream.

\subsubsection{Light Optical Microscopy}

Light optical microscopy (LOM) images were taken at $100 \mathrm{X}$ to distinguish features at low magnification. Figure 6 shows specimens exposed in the cathode stream. The H214 specimens show a significant amount of dark stained areas in the oxide suggesting some variation in composition across the surface. The H230 and HR120 specimens appear very uniform and mostly devoid of any specific features. The $800 \mathrm{H}$ specimen shows some darker regions which were somewhat evident in the photographs above.

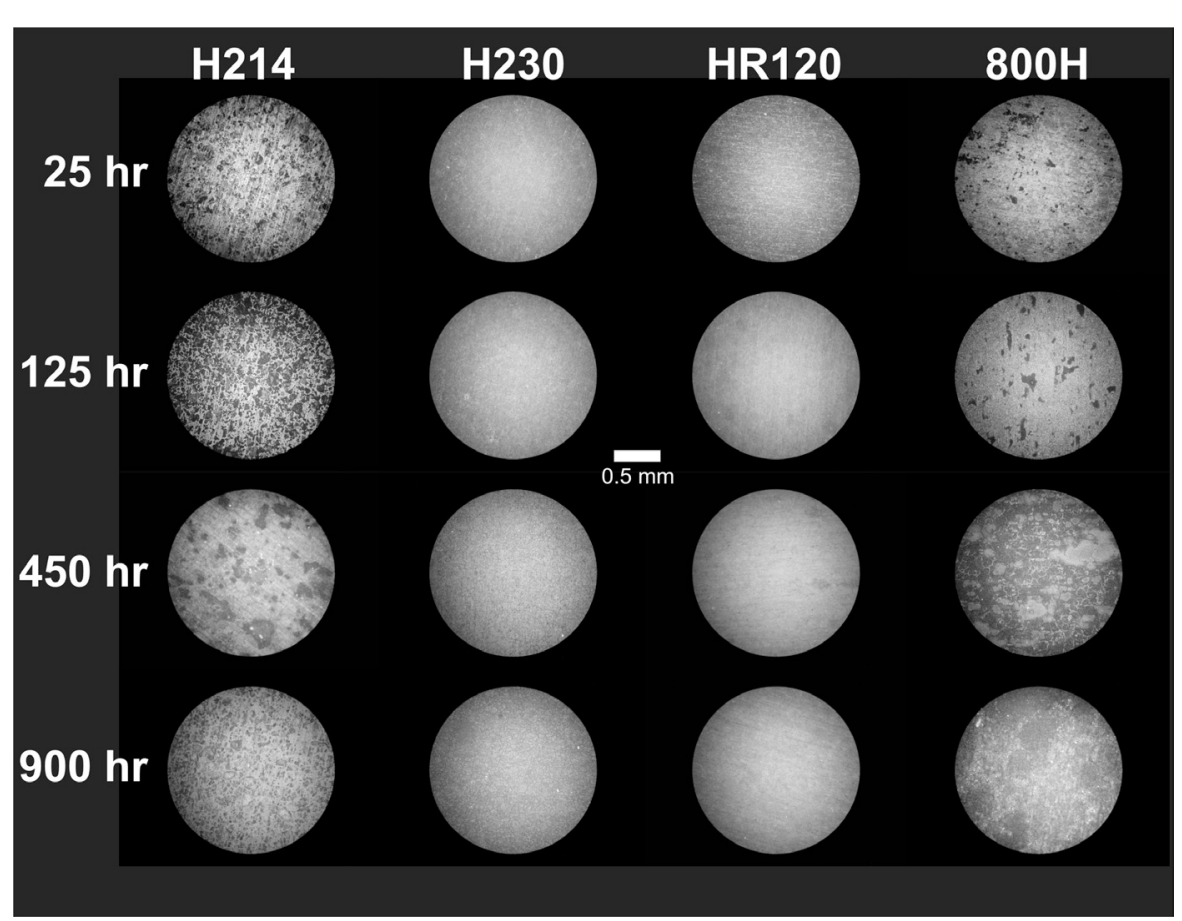

Figure 6. LOM of specimens exposed to the cathode stream. 
Figure 7 shows specimens exposed to the anode stream. Similar observations to that of specimens from the anode stream can be made with a couple of exceptions. The $800 \mathrm{H}$ specimens are much more uniform in texture. Another difference (difficult to observe at $100 \mathrm{X}$ ) is the significant crystalline texture for all the chromia formers. For the H230 and HR-120 the crystallinity is isolated while for the $800 \mathrm{H}$ the entire surface is highly textured with crystallites.

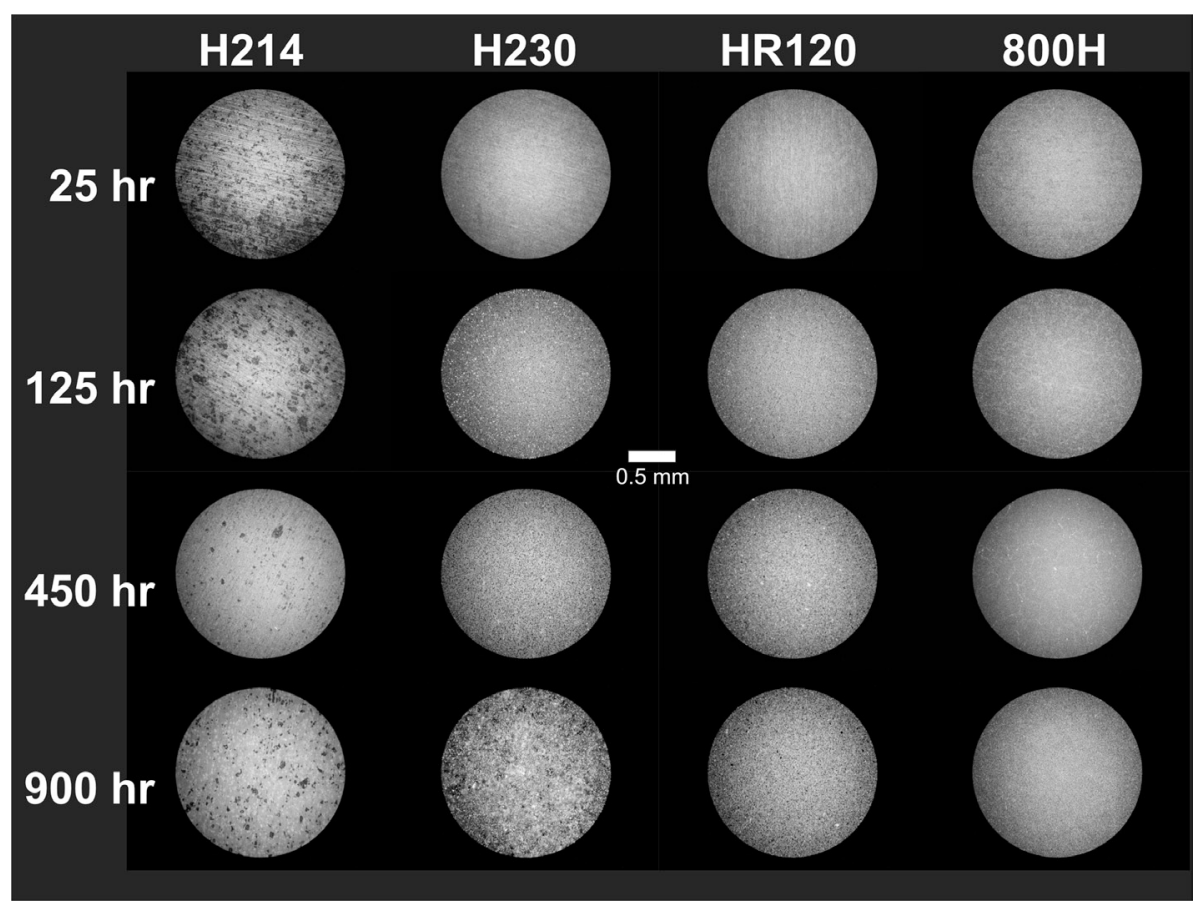

Figure 7. LOM of specimens exposed to the anode stream.

Figure 8 shows two high magnification images taken for $\mathrm{H} 230$ and $800 \mathrm{H}$ exposed for 125 hours demonstrating this crystalline texture. Note that for the H230 specimen exposed for 900 hours there are star-like crystallites that appear to be a precipitate on the surface.

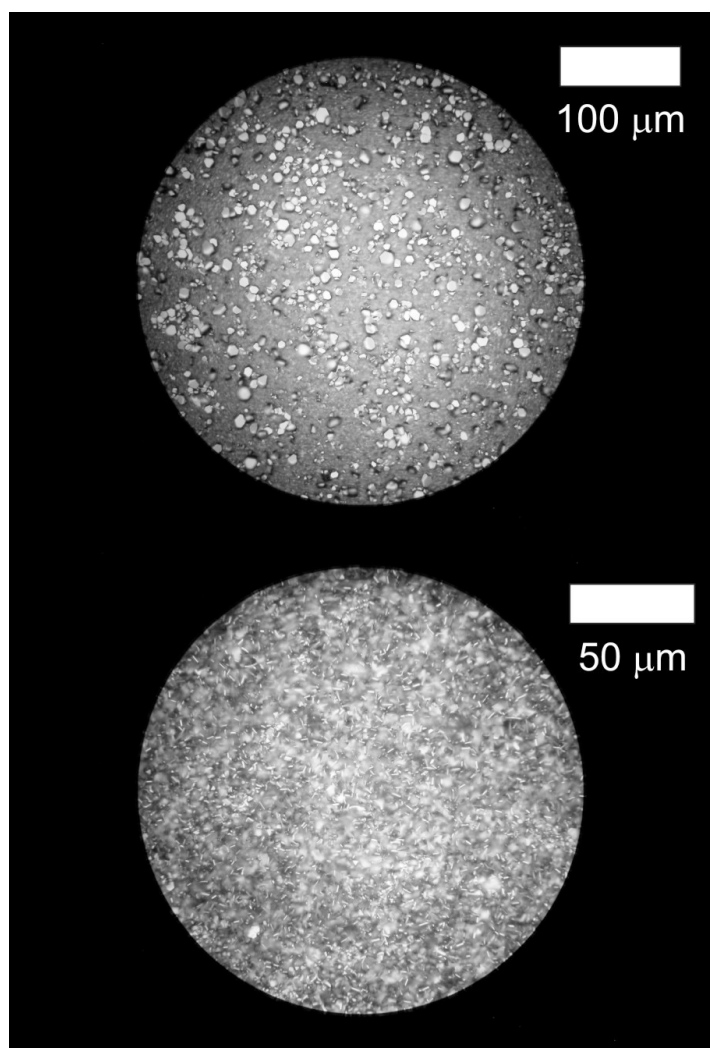

Figure 8. LOM micrographs of specimens exposed to the anode stream for 125 hours. Top micrograph is $\mathrm{H} 230$ at $500 \mathrm{X}$ and bottom is $800 \mathrm{H}$ at $1000 \mathrm{X}$. 


\subsubsection{Gravimetric analysis}

Gravimetric analysis was used to determine the weight gain during exposure. Weight gain was used to calculate the oxide film thickness. Each specimen was weighed prior to and after exposure to determine weight gain which is reasonably assumed to be oxygen addition. This assumes no loss of material, either through chromium evaporation (see Section 4 for additional details) or spalling. The weight gain was scaled to the geometrically calculated surface area (determined using a micrometer). Oxide thickness was calculated using the known density for $\mathrm{Cr}_{2} \mathrm{O}_{3}$ for chromia formers (H230, HR-120, and $\left.800 \mathrm{H}\right)$ and $\mathrm{Al}_{2} \mathrm{O}_{3}$ for the lone alumina former (H214). Figures 9-10 show weight gain data and values calculated from them. As expected, the thickness increases for all specimens with exposure time.

Note that an anomalous increase in weight was observed for the longest exposed H230 specimen in anode stream. This specimen clearly picked up external material (likely carbon) from an external source. A repair made to the specimen boats using alumina paste is the likely source. The data point was removed from Figure 10 for clarity of discussion. For both environments the alumina forming H214 demonstrated the superior oxidation resistance which is known to exist for $\mathrm{Ni}-\mathrm{Cr}$ alloys containing over $4 \mathrm{wt} \% \mathrm{Al} .{ }^{1} \mathrm{On}$ the other end of the spectrum the $800 \mathrm{H}$ specimen has the largest weight gain in both gas streams. Both $\mathrm{H} 230$ and H214 showed very similar oxidation growth curves. No significant difference in the two environments can be seen with exception to $800 \mathrm{H}$ which showed a significantly greater oxidation in the cathode stream where the oxide was almost twice as thick. This was the thickest calculated oxide for any of the specimens at $4.48 \mu \mathrm{m}$. It is worth noting that this same material displayed a several times thicker oxide in testing performed at $950^{\circ} \mathrm{C}$ previously and was the least stable alloy in those tests.

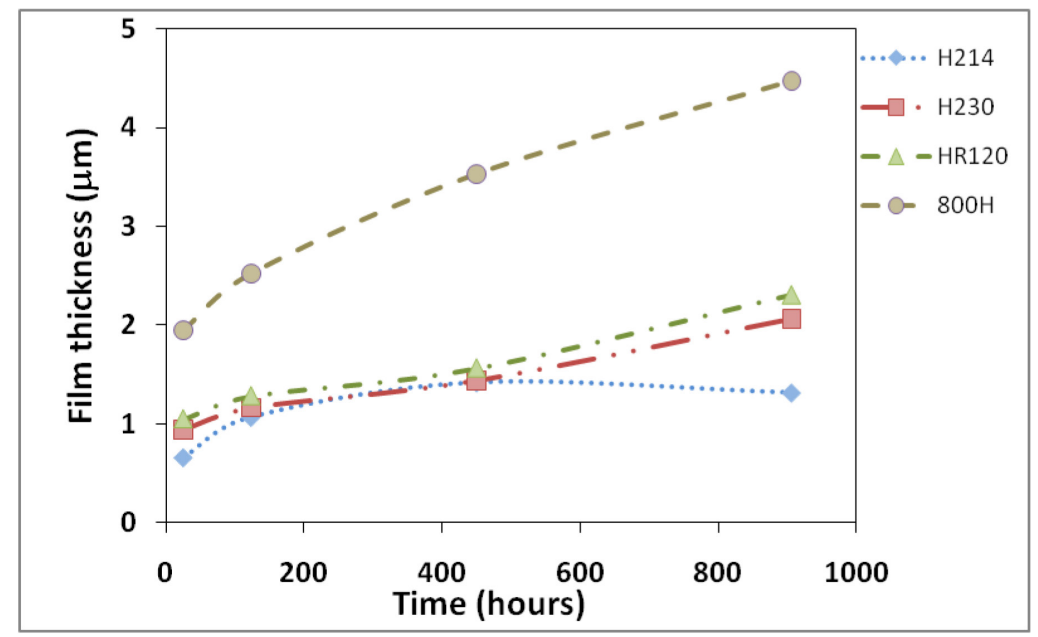

Figure 9. Weight gain versus time for specimens exposed to the cathode stream. 


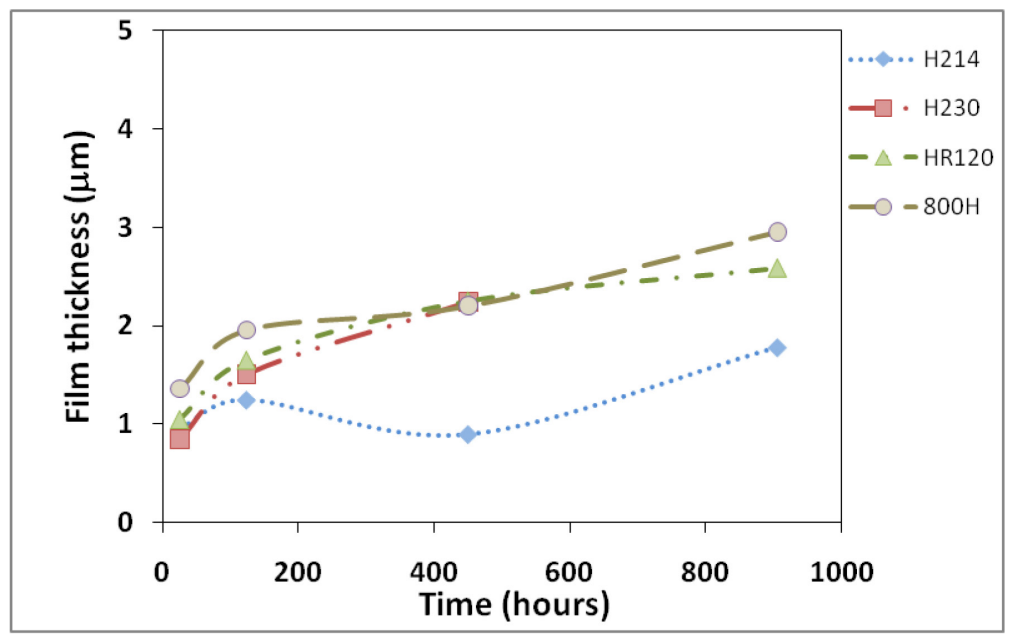

Figure 10. Weight gain versus time for specimens exposed to the anode stream.

Another way to represent the gravimetric data is to plot the oxidation rate versus time. This was performed by taking the calculated oxide thickness and dividing by the total exposure time. The resulting value is the average oxidation rate over the period of exposure and a different way of describing the protecting nature of the oxide films. This analysis has been performed for Figures 11-12 below. In all cases the calculated rate has dropped to or below $5 \mathrm{~nm} / \mathrm{hr}$. These values would continue to drop further as this number is not an instantaneous value but an average growth rate for the time exposed. As has been shown, most of the oxidation occurs in the first 100 hours, thus skewing the calculation somewhat to higher values. In addition, the actual rate should continue to drop as the oxidation rates follow an parabolic decay unless spalling occurs. ${ }^{2}$ However, these plots do serve as a demonstration of the stability of these oxides under these environments.

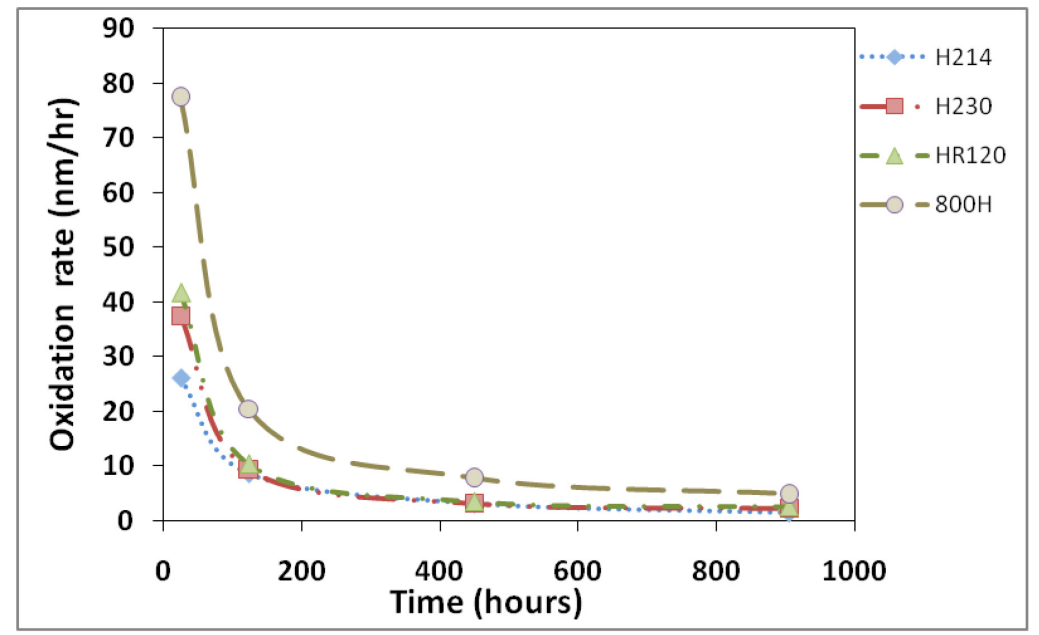

Figure 11. Oxidation rate measured for specimens exposed to the cathode stream. 


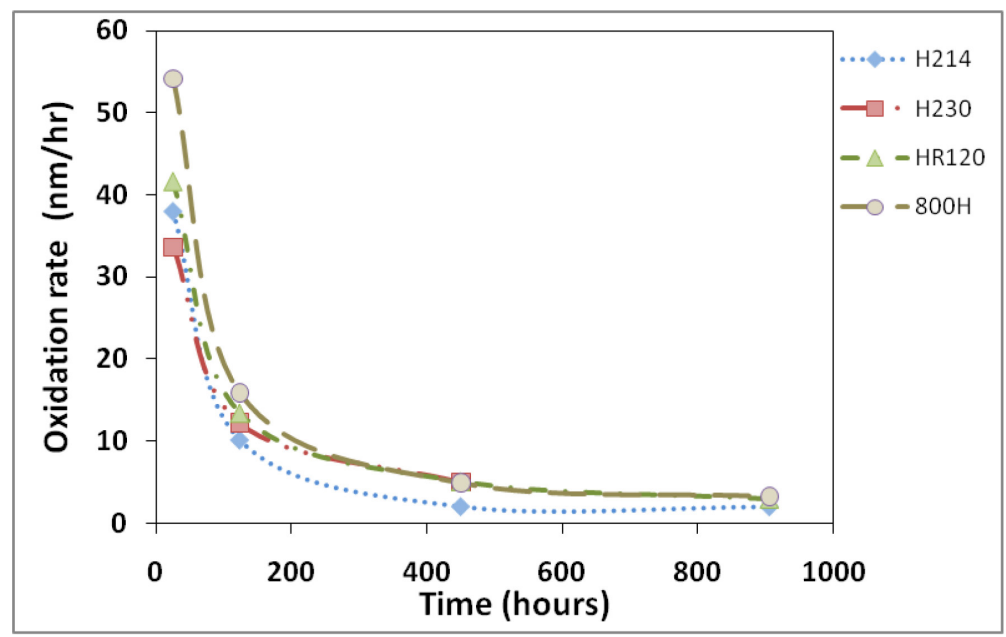

Figure 12. Oxidation rate versus time for specimens exposed to the anode stream.

\subsubsection{Metrology}

Metrology analysis was performed using OP on all exposed specimens and witness specimens not exposed after surface finishing. This method provides a three dimensional map of the surface allowing surface roughness to be evaluated and some larger textural features to be examined. Figures 13-14 show data for the cathode and anode streams respectively. Witness specimens of each alloy were measured to establish a baseline surface roughness plotted as 0 hours exposure. The value for the average roughness $\left(R_{a}\right)$ was calculated in the instrument software using a $599 \mu \mathrm{m} \times 456 \mu \mathrm{m}$ area image. $R_{a}$ is typically referred to as root mean square (RMS) roughness and is a statistical value useful for assessing the topological variation. As the specimens have a relatively smooth finish (600 grit final polish) prior to exposure, surface oxidation has increased the roughness for all alloys. Most of the alloys showed a dramatic increase in surface roughness for the first two specimens with subsequent specimens having only slightly more (or less) roughness. The reduction in roughness for certain specimens might result from complete formation of a similar texture across the surface at later times. Some specimens showed a slight decrease in roughness for the initial specimen such as for HR-120 in cathode stream or $800 \mathrm{H}$ in anode stream (see Figure 13). The reason for this is not clear and this instrument does not possess the X-Y resolution required to observe the microstructures formed. One interesting note is that $\mathrm{H} 214$ was the roughest specimen from the cathode stream, which also possessed the thinnest oxide film. H214 was also the smoothest specimen exposed to the anode stream where it also possesses the thinnest oxide film. Conversely, it was the roughest alloy yet had the lowest oxide thickness in the cathode stream. Note that SEM showed two separate textures for the cathode stream exposed H214 specimen which may account for the roughness (see Figure 16 below). Also note that the H230-OX-4 was excluded from Figure 14 due to the $\mathrm{R}_{\mathrm{a}}$ of over $5,000 \mathrm{~nm}$ due to surface contamination. 


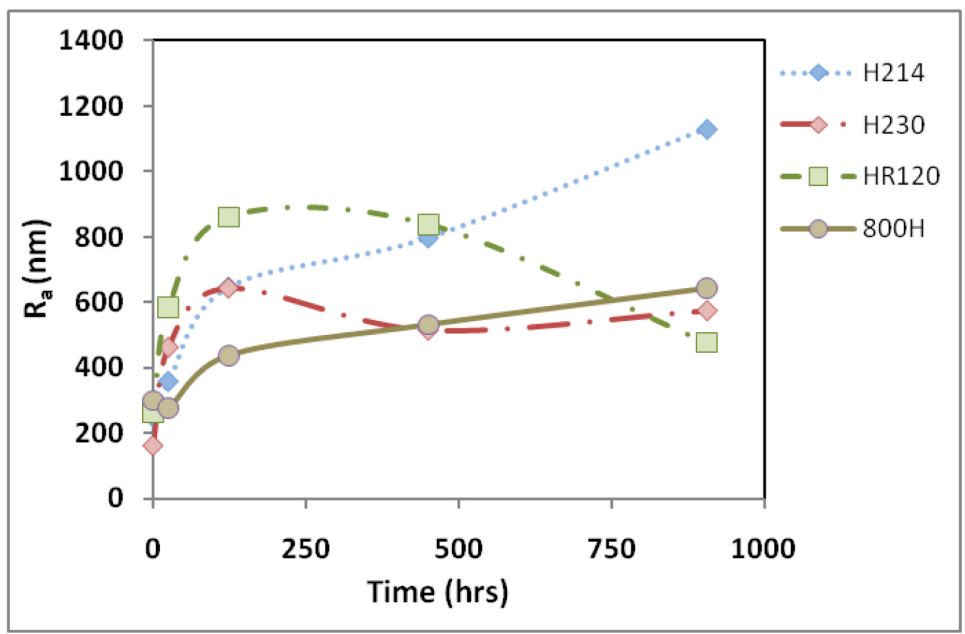

Figure 13. Surface roughness $(\mathrm{Ra})$ measured for specimens exposed to the cathode stream. A value for the witness specimen is at $0 \mathrm{hrs}$.

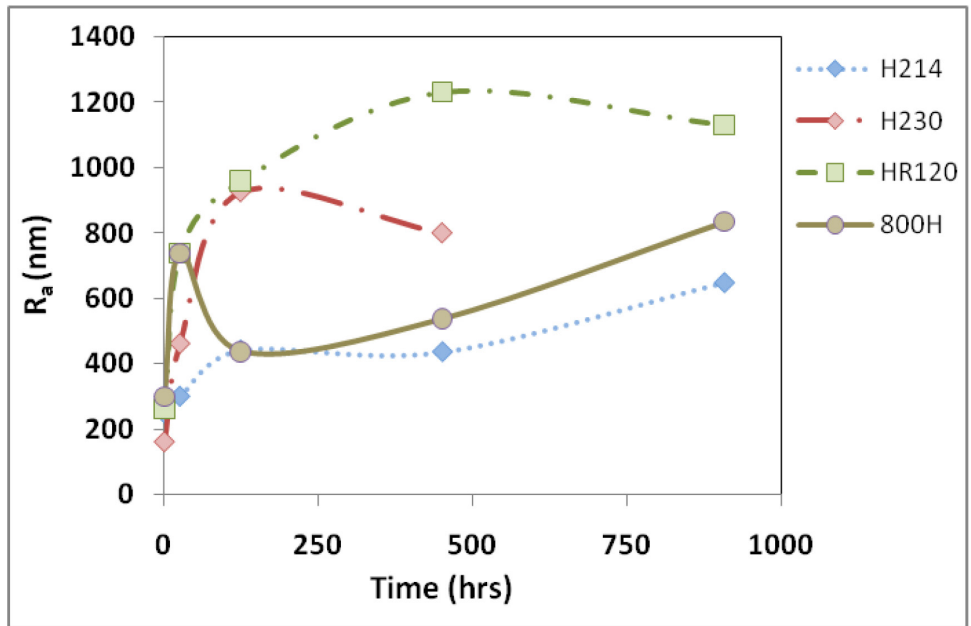

Figure 14. Surface roughness $\left(R_{a}\right)$ measured for specimens exposed to the anode stream. A value for the witness specimen is at $0 \mathrm{hrs}$.

Figure 15 is an example OP micrograph taken of the $800 \mathrm{H}$ specimen exposed for 450 hours. This micrograph shows details of oxidation outlining the grain boundaries. This behavior was observed in other alloys but was most pronounced for $800 \mathrm{H}$. The protruding features suggest that the grain boundaries have a higher oxidation rate, likely due to enhanced diffusion. ${ }^{2}$ 


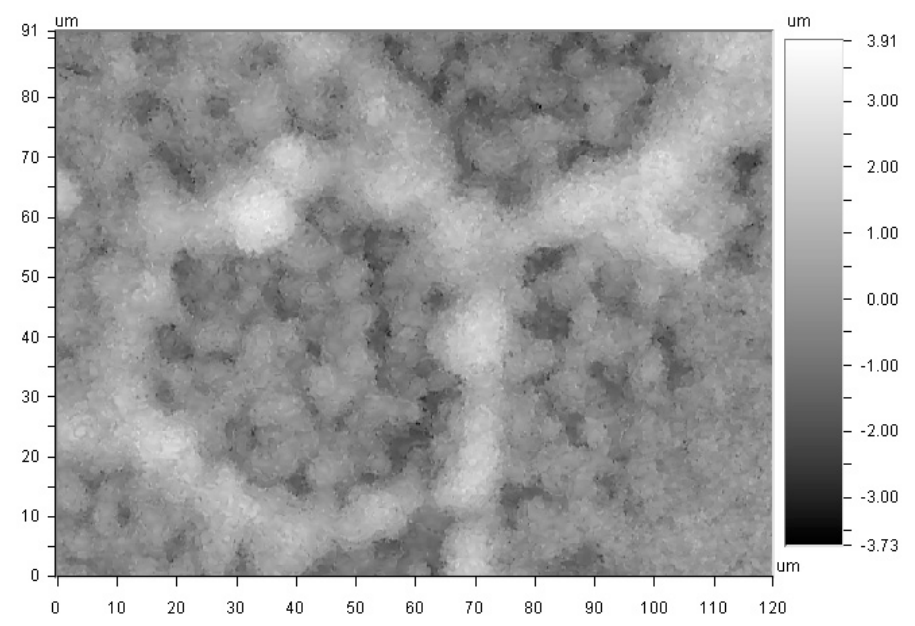

Figure 15. OP micrograph for $800 \mathrm{H}-\mathrm{HY}-3$ exposed for $450 \mathrm{hrs}$ in the cathode stream.

\subsubsection{Scanning Electron Microscopy}

Scanning Electron Microscopy (SEM) was performed for the longest exposed specimen of each alloy in both environments. Surface SEM measurements were performed then the specimen was cut in half for cross-sectional analysis. Energy Dispersive Spectroscopy (EDS) was used to determine location specific elemental composition.

Figure 16 shows SEM micrographs of specimens exposed to the cathode stream. For the chromia formers the specimens show uniform texture while the alumina former has two distinct microstructures. EDS data of the chromia formers show primarily $\mathrm{Cr}-\mathrm{Mn}$ in the oxide, likely a mix of chromia and Cr-Mn spinel phases. The spinel phase is a desired stable phase which forms due to the small amount $(<1 \%) \mathrm{Mn}$ added to these alloys ${ }^{1}$. Using data from metrology images it is known that the lighter phase for $\mathrm{H} 214$ is higher and thus likely a thicker oxide than the surrounding darker regions. The darker areas also show evidence of polishing marks. These brighter regions also contain more chromia than the surrounding darker regions which are primarily alumina. Further cross-sectional analysis should help determine the thickness of the oxide in these two areas. 

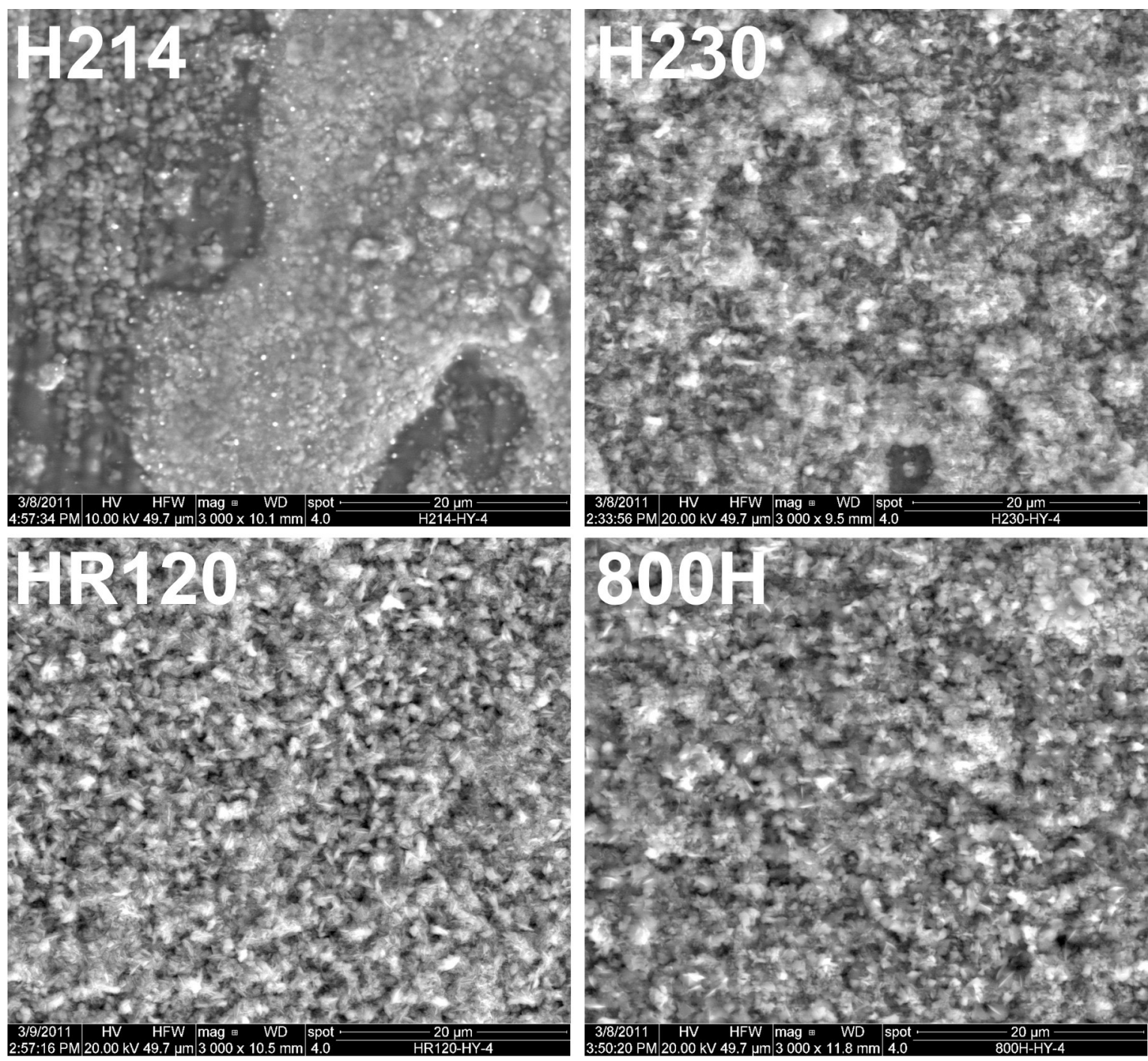

Figure 16. SEM micrographs (3000X) for specimens exposed to the cathode stream.

Figure 17 shows SEM micrographs of specimens exposed to the anode stream. A universal observation is that the alloys all show a more defined crystalline character that in the cathode stream. The reason for this is not known but agrees with LOM data described above. Note that the H230 specimen was contaminated and thus much of the crystalline character is partially obscured. As described in the LOM micrographs above, crystalline characteristics were noted for all the chromia formers in anode stream. While the crystal structure appears quite different, the EDS composition data is quite similar to that observed in cathode stream. 

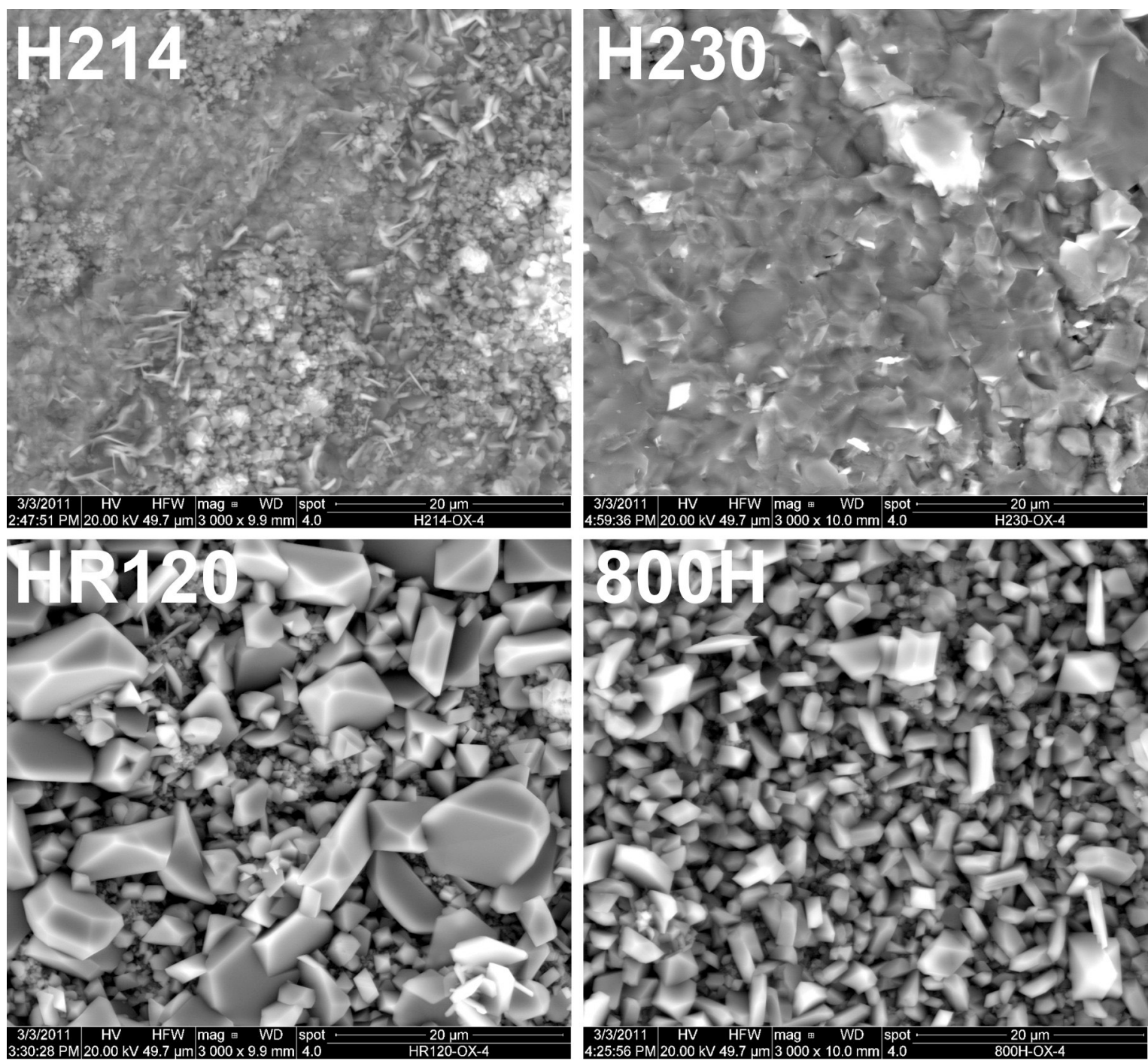

Figure 17. SEM micrographs (3000X) for specimens exposed to the anode stream.

EDS spot analysis was performed during SEM analysis providing atomic\% values of elements in the oxide films. For brevity, an average value for the EDS spot analyses is provided in Table 4. The H214 shows a mix of alumina and chromia phases while the remaining specimens have chromium-manganese oxides, likely the spinel phase. An anomalous amount of Si was observed for specimens in the cathode stream. 
Table 3-4 Atomic \% composition of elements from EDS spot analysis after 900 hours exposure.

\begin{tabular}{|l|c|c|c|c|c|c|c|c|}
\hline Atomic \% & $\mathbf{O}$ & $\mathbf{C r}$ & $\mathbf{M n}$ & $\mathbf{A l}$ & $\mathbf{N i}$ & $\mathbf{F e}$ & $\mathbf{T i}$ & $\mathbf{S i}$ \\
\hline $\begin{array}{l}\text { H214 } \\
\text { HY stream }\end{array}$ & 45.33 & 17.04 & 0.83 & 21.87 & 4.23 & 0.72 & 0 & 10.02 \\
\hline $\begin{array}{l}\text { H230 } \\
\text { HY stream }\end{array}$ & 48.52 & 41.34 & 5.32 & 0 & 1.24 & 0.62 & 0 & 2.95 \\
\hline $\begin{array}{l}\text { HR120 } \\
\text { HY stream }\end{array}$ & 47.78 & 40.49 & 7.61 & 0 & 0.36 & 0.73 & 0 & 3.02 \\
\hline $\begin{array}{l}800 \mathrm{H} \\
\text { HY stream }\end{array}$ & 47.97 & 40.16 & 8.6 & 0 & 0 & 0.99 & 0.59 & 1.68 \\
\hline $\begin{array}{l}\text { H214 } \\
\text { OX stream }\end{array}$ & 37.75 & 7.44 & 0 & 40.26 & 13.63 & 0.92 & 0 & 0 \\
\hline $\begin{array}{l}\text { H230 } \\
\text { OX stream }\end{array}$ & 44.77 & 30.09 & 1.01 & 0.45 & 22.73 & 0.53 & 0 & 0.42 \\
\hline $\begin{array}{l}\text { HR120 } \\
\text { OX stream }\end{array}$ & 53.02 & 43.95 & 2.56 & 0 & 0.25 & 0.23 & 0 & 0 \\
\hline $\begin{array}{l}800 \mathrm{O} \\
\text { OX stream }\end{array}$ & 51.56 & 34.85 & 12.46 & 0 & 0.29 & 0 & 0.85 & 0 \\
\hline
\end{tabular}

\subsubsection{Specimen Analysis Discussion}

The analysis of the specimens has provided detailed knowledge of the oxidation behavior during the testing. While more data is to be gathered on these specimens, the data shows stable oxides were grown on all alloys tested in both gas streams. This finding suggests that these alloys would all be suitable for service as manifold materials with a HTSE system under the tested conditions. This does not complete the testing as this isolated test does not consider other important factors. Elevated pressures may have a significant impact on the oxidation rates due to larger concentrations of oxidizing agents (oxygen and steam) and hydrogen at the metal surfaces. The effect of pressure will need to be ascertained in future testing activities. As is well known for chromia forming alloys, pushing the temperature above $900^{\circ} \mathrm{C}$ would result in evaporation of chromium. In fact this process may also occur at much lower temperatures than tested here. Manganese containing alloys form a $\mathrm{MnCr}_{2} \mathrm{O}_{4}$ spinel in the outer oxide layer, which has been attributed to lowering the oxidation resistance at high temperature. ${ }^{3}$ However, $\mathrm{MnCr}_{2} \mathrm{O}_{4}$ spinels forming under high-temperature oxidation lower chromium vaporization rates. ${ }^{4-5}$ Discussion of future testing activities for assessing chromium evaporation is provided in Section 4 below.

\section{SUMMARY}

In summary, the initial campaign for the reconstituted MISTER test system was a success. The new test setup is a significant improvement in both design and capabilities. Initial tests involved a suite of four important alloys for high temperature service. Testing was performed under conditions modeled for the anode (oxygen + nitrogen gases) and cathode (hydrogen + steam gases) manifolds for HTSE. Four specimens were exposed in each environment for varying time periods to track the rate of oxidation. Visual observation showed no evidence of film adhesion problems. Weight gain was used to estimate the oxide film thickness and oxidation rate. As expected, oxidation rate decreased with time to below $5 \mathrm{~nm} / \mathrm{hr}$ for all alloys indicating passivating behavior. Metrology of the surfaces indicated an initial increase in RMS roughness which followed the oxidation rate trend toward stabilizing with time. SEM and EDS was 
used to measure surface microstructure and chemical composition. Larger well defined crystallites were observed on chromia formers in the anode stream while less distinct microcrystalline oxides were observed in the cathode stream.

The work performed in this report describes an initial testing campaign to demonstrate the MISTER system, determine any existing issues with the setup and provide some preliminary data at lower temperatures currently anticipated for HTSE. Additional materials testing activities will be needed for HTSE support. While future testing activities will be described in a future test plan, an outline of possible future testing is provided below.

Detection of evaporated chromium should be an aspect of future test plans due to the potential for deleterious effects of chromium on the electrolyzers. ${ }^{6}$ The MISTER apparatus could be reconfigured to perform this measurement by using a condensing medium downstream of the corrosion specimen. This medium would be analyzed for chromium by leaching and subsequent elemental analysis. If chromium is a significant problem, use of alumina forming alloys such as Haynes 214 should be a suitable alternative based on elemental composition of the oxide. Coatings have also been used to provide diffusion barriers to oxidation and chromium vaporization processes, particularly for the electrolysis cell interconnects.

While testing at ambient pressure is an important demonstration, feasible electrolysis units will need to operate at elevated pressure according to projected designs. The MISTER has been designed to perform elevated pressure tests. The effects of pressure are not well understood, but the increased reactive collisions at the oxide surface could change the texture and stability of the oxides. An increase in hydrogen pressure could also increase loading of hydrogen in the metal itself and should be evaluated. Penetration tests could be performed to determine the rate of hydrogen transfer by modifying the manifold slightly and collecting gas for analysis.

Cell interconnects are important components in the HTSE cells as they form the internal contacts that deliver power to the cells. These components must maintain conductive surfaces to prevent voltage drops which reduce efficiency through resistive heat loss. To prevent these losses, coatings are utilized where the oxide formed is both conductive and prevents further oxidation of the base alloy under the coating. This is a very active area of research throughout the world where applied to solid oxide fuel cells (SOFC) which are essentially an electrolysis cell operated in reverse. A relationship exists with Montana State University (MSU) to deliver interconnect coatings for testing in the MISTER. MSU has significant capabilities in coating technologies and has expressed significant interest in meeting HTSE needs.

Finally, parts of the HTSE system will have differential environments, where reactive gas environments of the two manifold gas types will be separated by metal components. The effect of a differential environment is not well known and thus tests should be designed to determine if premature degradation occurs due to the differential environment.

While the MISTER was commissioned to perform testing of materials for HTSE, plans were made during design phase to study a variety of environments of interest to NGNP. As described in MISTER overview (Section 2.1), the manifold system was design to incorporate a variety of gases in order to increase flexibility should other projects require materials testing. Testing of pre-stressed specimens could also be performed with minimal changes to the system. The effect of gas composition changes and cycling between extremes could also be performed if needed.

One example of a new materials testing need for NGNP outside HTSE involves metals bonded by diffusion bonding. This joining method is being considered as a fabrication method for compact heat exchangers. This is a relatively new joining method where grain growth across the interface of two metal parts while heated/compressed in vacuum. This method allows unique microchannel architectures to be made using plate stock. While the alloys composing the joint may be well studied, diffusion processes and phase transformations will result in concentration profiles of different components and precipitates 
and should affect high-temperature oxidation performance. The MISTER experimental system could be utilized to study the oxidation behavior of the joined interfaces.

\section{REFERENCES}

1. G. D. Smith, The Role of Protective Scales in Enhancing Oxidation Resistance, Special Metals, Huntington, West Virginia.

2. H.V. Atkinson, A Review of the Role of Short-Circuit Diffusion in the Oxidation of Nickel, Chromium, and Nickel-Chromium Alloys Oxidation of Metals, 54, 1985, 177.

3. A. L. Marasco and D. J. Young, 1991, "The Oxidation of Iron-Chromium-Manganese Alloys and $900^{\circ} \mathrm{C}, "$ Oxidation of Metals 36 (1991) 157.

4. G. R. Holcomb, 2009, "Steam Oxidation and Chromia Evaporation in Ultrasupercritical Steam Boilers and Turbines," Journal of the Electrochemical Society 156, 2009, C292.

5. G. R. Holcomb and D. E. Alman, 2006, "The Effect of Manganese Additions on the Reactive Evaporation of Chromium in Ni-Cr- Alloys," Scripta Materialia 54, 2006, 1821.

6. M. Stanislowski, E. Wessel, T. Markus, L. Singheiser and W.J. Quadakkers, 2008, "Chromium Vaporization from Alumina Forming and Aluminized Alloys," Solid State Ionics, 2406. 